This manuscript is a preprint and has been submitted for publication in Gondwana Research. The manuscript had been reviewed and published. Please feel free to contact any of the authors; we welcome feedback 


\title{
Plume - Lid interactions DURing the ArCheAn AND IMPLICATIONS FOR THE GENERATION OF EARLY CONTINENTAL CRUST
}

\author{
A Preprint
}

\author{
Andrea Piccolo \\ Institute of Geosciences \\ Johannes Gutenberg University \\ Mainz, Germany. \\ piccolo@uni-mainz.de \\ Richard W. White \\ School of Earth and Environmental Sciences \\ University of St Andrews \\ St Andrews, UK
}

\author{
Boris J.P. Kaus \\ Institute of Geosciences \\ Johannes Gutenberg University \\ Mainz, Germany.
}

\author{
Georg S. Reuber \\ Institute of Geosciences \\ Johannes Gutenberg University \\ Mainz, Germany.
}

Friday $21^{\text {st }}$ May, 2021
Richard M. Palin

ent of Geology and Geological Engineering

Colorado, USA

\begin{abstract}
Many Archean terranes are interpreted to have a tectonic and metamorphic evolution that indicates intra-crustal reorganization driven by lithospheric-scale gravitational instabilities. These processes are associated with the production of a significant amount of felsic and mafic crust, and are widely regarded to be a consequence of plume-lithosphere interactions. The juvenile Archean felsic crust is made predominantly of rocks of the tonalite-trondhjemite-granodiorite (TTG) suite, which are the result of partial melting of hydrous metabasalts. The geodynamic processes that have assisted the production of juvenile felsic crust, are still not well understood. Here, we perform 2D and 3D numerical simulations coupled with the state-of-the-art of petrological thermodynamical modelling to study the tectonic evolution of a primitive Archean oceanic plateau with particular regard on the condition of extraction of felsic melts. In our numerical simulations, the continuous emplacement of new, dry mafic intrusions and the extraction of the felsic melts, generate an unstable lower crust which drips into the mantle soon after the plume arrival. The subsequent tectonic evolution depends on the asthenosphere $T_{P}$. If the $T_{P}$ is high enough $\left(\geq 1500^{\circ} \mathrm{C}\right)$ the entire oceanic crust is recycled within 2 Myrs. By contrast at low $T_{P}$, the thin oceanic plateau slowly propagates generating plate-boundary like features.
\end{abstract}

2

\section{Introduction}

Archean continental crust preserved on Earth occurs above old, strong and buoyant cratonic lithosphere. In some cases, the geological features recorded in these Archean terranes resembles those commonly seen in Phanerozoic terranes, such as horizontal displacements consistent with opening of basins (e.g. West Pilbara) Van Kranendonk et al. (2007) or orogenic processes (e.g. Itsaq) (Nutman et al., 2013). In many others, Archean terranes testify that high-grade metamorphism, production of felsic crust and plume-related magmatism happened simultaneously (Van Kranendonk et al., 2015; Chardon et al., 1996; Choukroune et al., 1995). 
Archean continental crust is a mixture of mafic and felsic components (Kamber, 2015; Condie, 1981, 1993). The felsic crust is composed of tonalite-trondhjemite-granodiorite (TTG) magmas with a minor contribution of potassic granitoids (Moyen, 2011; Moyen \& Stevens, 2006), whereas mafic crust is composed of several types of rocks spanning from ultramafic to iron tholeiites (Anhaeusser, 2014). Juvenile Archean TTGs can be produced by many mechanisms, although partial melting of a hydrated metabasalt (Johnson et al., 2017; White et al., 2017; Palin et al., 2016b,a; Moyen \& Martin, 2012; Moyen, 2011) is accepted as being most prevalent. The trace and major element profiles for TTG magmas suggest that the partial melting must have occurred at medium-high pressure and high temperature in the presence of garnet, rutile, amphibole \pm plagioclase (Palin et al., 2016a; Moyen \& Martin, 2012). The extraction of felsic melts leaves behind a mafic residuum that is denser than the underlying mantle (Piccolo et al., 2019; Palin et al., 2016a) and more prone to be delaminated or dripped off.

Many Archean terranes (e.g. East Pilbara) show that a close relationship exists between felsic melt production and vertical reorganization of the crust (partial convective overturn) (Van Kranendonk et al., 2004; Chardon et al., 1998; Collins et al., 1998; Bouhallier et al., 1995). These processes result in the classical structure of greenstone belts: the dome-and-keel geometries, in which felsic granitoids rise to shallow crustal levels, while mafic crust sinks. These structures are atypical for convergent margin settings and they are more consistent with plume-lithosphere interactions (Van Kranendonk, 2010; Van Kranendonk et al., 2004; Choukroune et al., 1995). The gravitational instabilities allow for an active exchange between shallow-surface environment and the mantle reservoir (Lee et al., 2006; Bédard, 2006; Zegers \& van Keken, 2001). All these processes may feed back and influence the mafic crust and the petrogenesis of juvenile TTGs. Their occurrence depends on the intensity of magmatic processes and on the thermal and mechanical state of the convecting mantle.

The mantle potential temperature $\left(T_{P}\right)$, the degree of radiogenic heat production and the convection style exert a strong control on plume-lithosphere dynamics (Jellinek et al., 2002; Schubert et al., 2001; Solomatov, 1995; Davaille \& Jaupart, 1993). The absence of strong viscosity contrast within the convecting mantle and the high production of radiogenic heat can reduce plume activity or change their form, making them tail-less (Jellinek et al., 2002). It is still unclear what range of values of $T_{P}$ are representative for the Archean, with estimates spanning from 1400 to $1650{ }^{\circ} \mathrm{C}$ (Aulbach \& Arndt, 2019; Ganne \& Feng, 2017; Kamber, 2015; Herzberg et al., 2010). If $T_{P}$ ranges are in the lower end of these estimates $\left(<1500^{\circ} \mathrm{C}\right)$, then the inferred high $T_{P}$ Herzberg et al. (2010) is only an artifact of overturn events and the preserved Archean cratons formed at the top of overturn upwelling zones (Bédard, 2018).

Geodynamic and petrological modelling has been progressively integrated with field observations with quantitative/qualitative data to provide new insight into the tectonics of Archean terranes. Many numerical experiments base the compositional evolution on simplified parametrizations (e.g. (Fischer \& Gerya, 2016; Jain et al., 2019; Sizova et al., 2015, 2014)) and/or employed only 2D numerical experiments (e.g. (Piccolo et al., 2019; Sizova et al., 2015)). These numerical experiments provide powerful insights, however the results may be biased by the 2D approach or by the resolution at which the crust is resolved, which is particularly important for global scale numerical experiments (e.g. Jain et al. (2019); Rozel et al. (2017)). The existing 3D numerical examples, instead, focus on the structural evolution, and do not explore the effect of felsic crust extraction (Fischer \& Gerya, 2016; Gerya et al., 2015). In order to have a comprehensive view of the evolution of early Earth, it is necessary to explore the compositional and structural evolution of the Archean terranes combining petrological forward modelling with geodynamic 3D numerical simulations.

Here, we present a new advance towards integrating petrological phase diagram in a 3D numerical framework. We study the generation and short-term evolution of Archean terranes and the effects of the upper mantle $T_{P}$ on the evolution of the primitive crust. Our results show that as a function of the upper mantle $T_{P}$, plume-lithosphere interaction yields different compositional and structural evolution of the Archean terranes. Further, we show that vertical tectonic deformation is not exclusively found in plate-tectonic like regimes and we demonstrate several different mechanisms that may produce felsic crust in a stagnant lid geodynamic scenario.

\section{Methods}

\subsection{Numerical Modeling}

The geodynamic simulations were performed using LaMEM; a marker in cell, finite difference 3D petro-thermomechanical code (Reuber et al., 2018; Kaus et al., 2016), which solves the fundamental continuum mechanics conservation equations for mass, momentum and energy.

The mass conservation equation is solved assuming that the materials are incompressibile: 


$$
\frac{\partial v_{i}}{\partial x_{i}}+S=0
$$

$v_{i}$ is the velocity vector component along the $x_{i}$ direction (i.e $x, y, z$ ). In order to incorporate the compaction and expansion effects due to the melt extraction, we introduced a source/sink (S, see Tab. S1 and below for further explanations) term in the non-linear residual calculations. $\mathbf{S}$ has an indirect effect on the momentum equation, because it affects the pressure and velocities. Therefore, the momentum equation retains its canonical form:

$$
\frac{\partial \tau_{i j}}{\partial x_{j}}-\frac{\partial P}{\partial x_{i}}+\rho g_{i}=0
$$

where $\tau_{i j}$ is the deviatoric stress tensor, $P$ is the pressure, $\rho$ is the density and $g_{i}$ is the gravity vector component along the $i$ direction.

LaMEM employs viscous-elasto-plastic rheological constitutive equations that connect the deviatoric stress tensor components $\left(\tau_{i j}\right)$ to the total strain rate tensor components $\left(\dot{\varepsilon}_{i j}\right)$ as follows:

$$
\begin{gathered}
\dot{\varepsilon}_{i j}=\dot{\varepsilon}_{i j}^{v i s}+\dot{\varepsilon}_{i j}^{e l}+\dot{\varepsilon}_{i j}^{p l}=\frac{\tau_{i j}}{2 \eta_{e f f}}+\frac{\stackrel{\diamond}{\tau}_{i j}}{2 G}+\dot{\gamma} \frac{\partial Q}{\partial \tau_{i j}} \\
\grave{\tau}_{i j}=\frac{\partial \tau_{i j}}{\partial t}+\tau_{i k} \omega_{k j}-\omega_{k i} \tau_{k j} \\
\omega_{i j}=\frac{1}{2}\left(\frac{\partial v_{i}}{\partial x_{j}}-\frac{\partial v_{j}}{\partial x_{i}}\right)
\end{gathered}
$$

Where $\dot{\varepsilon}_{i j}$ is the total strain rate tensor, the superscript $e l, v i s, p l$ indicate the elastic (el), viscous (vis) and plastic $(p l)$ strain rate. $\stackrel{\diamond}{\tau}$ is the Jaumann objective stress rate, $G$ is the shear modulus. $\omega$ is the spin tensor, $\dot{\gamma}$ is the plastic multiplier, $Q$ is the plastic flow potential, which is equal to the second invariant of the deviatoric stress tensor $\left(\tau_{I I}\right)$, according to a dilatation-free non associative Drucker-Prager flow rule. $\eta_{e f f}$ is the viscosity which is computed using the following equation:

$$
\eta_{e f f}=\frac{1}{2} B_{n}^{-\frac{1}{n}}{\frac{1}{\varepsilon_{I I}^{n}}-1}^{\dot{n}^{n}} \exp \left(\frac{E_{a}+P V_{a}}{n R T}\right)
$$

$B_{n}$ is the pre-exponential factor, $n$ is the stress exponent, $\dot{\varepsilon}_{I I}$ is the second invariant of the strain rate tensor, $R$ is the gas constant, $E_{a}$ and $V_{a}$ are respectively the activation energy and volume.

The plastic rheology is enforced by the application of the Drucker-Prager failure criterion (Drucker \& Prager, 1952):

$$
Y=\tau_{I I}-\sin (\phi) P-C \cos (\phi) \leq 0
$$

$Y$ is the yield function, $\phi$ is the friction angle and $C$ is the rock's cohesion. During plastic deformation $C$ and $\phi$ can linearly decrease from the initial values $\left(C_{0}, \phi_{0}\right)$ to a final values $\left(C_{1}, \phi_{1}\right)$ simulating the progressive damage of a rock. The plastic weakening starts when materials accumulate at least 0.1 of total plastic strain and it stops when the material reaches a plastic strain of 1.0. The effective viscosity of the rocks is limited by a lower and upper cut-off $\left(10^{18}\right.$ and $10^{24} \mathrm{~Pa} \cdot s$ respectively). Due to the high temperatures most of the area that are partially molten reaches the lower-cut off viscosity. As a consequence we simplify the creep viscosity by neglecting the melt-weakening factor (used for example by Piccolo et al. (2019)).

Conservation of energy is computed according to:

$$
\begin{gathered}
\rho C_{p} \frac{D T}{D t}=\frac{\partial}{\partial x_{i}}\left(k \frac{\partial T}{\partial x_{i}}\right)+H_{a}+H_{s}+H_{r} \\
H_{a}=T \alpha\left(\frac{\partial P}{\partial x_{i}} v_{i}\right)
\end{gathered}
$$




$$
H_{s}=\left(\dot{\varepsilon}_{i j}-\dot{\varepsilon}_{i j}^{e l}\right) \tau_{i j}
$$

where $C_{p}$ is the heat capacity, $D T / d t$ is the objective temperature time derivative, $k$ is the heat conductivity, $H_{r}$ is the radiogenic heat productivity ( $H_{r}=\rho A$, where $A$ is the amount of heat produced per unit of mass). $H_{a}$ is the adiabatic heating and is computed according the eq. 9 (in which $\alpha$ is the thermal expansivity) while $H_{S}$ is the dissipative heating. We neglect latent heat of melting because its effect is negligible compared with shear and adiabatic heating.

\subsection{Melt extraction and petrological modelling}

\subsubsection{Melt extraction}

In the simulations, melt extraction and emplacement are considered to occur instantaneously. In each timestep the effective melt fraction is computed $\left(M^{*}\right)$ by subtracting the total melt extracted from the melt fraction interpolated from the phase diagram (see Fig.1). Then we evaluate whether the volumetric melt fraction is sufficient to trigger melt extraction. If $M^{*}$ is higher than a critical melt fraction threshold, $M_{t r s}$, a fixed quantity of melt escapes from the source, and its volume ( $V_{\text {ext }}$, extracted volume) is computed according to:

$$
V_{\text {ext }}= \begin{cases}P h_{\text {Rat }} d M d V, & \text { if } M^{*}-d M \geq M_{t r s} \\ P h_{\text {Rat }}\left(M^{*}-M_{t r s}\right) d V, & \text { if } M^{*}-d M<M_{t r s}\end{cases}
$$

Where $d V$ is the volume of the current finite difference cell, and $d M$ is the volumetric fraction of melt that escapes, and $P h_{R a t}$ is the volumetric fraction of the rock phase in the current cell. If the difference between $\mathrm{M}^{*}$ and $M_{t r s}$ is less than $d M$, the quantity of melt extracted is equal to it, and thus $M_{t r s}$ represents the minimum amount of melt that can be retained in a rock.

$d M$ represents the maximum volumetric fraction of melt that can be extracted from a source for a given timestep. This allows exploration of the cases in which melt extraction cannot compensate for melt production, e.g. if $d M$ exfiltration is less efficient than production of new melt, the average density of the partially molten area decreases, and thus its buoyancy increases. Moreover using a fixed $d M$ has two advantages: 1) it prevents instantaneous production of large volumes of crust; and 2) it prevents inducing a strong volumetric deformation due to the source/sink term in the mass conservation equations.

The total amount of melt extracted from the current rock phase is computed by integrating the volume extracted from each cell along the $z$ direction. The total volume of extracted melt must be corrected by a factor that depends on the ratio between the density of the melt and solid rock $\left(\rho_{\text {melt }} / \rho_{\text {solid }}\right.$, as in Wallner \& Schmeling (2016)):

$$
V_{\text {ext }}^{T o t}=\operatorname{Vol}_{\text {cor }} \sum_{k=0}^{n^{\text {end }}} V_{\text {ext }}(k)
$$

$V_{\text {ext }}^{T o t}$ is the total amount of melt extracted from a rock type along z direction at fixed $x, y$ coordinates; $V o l_{c o r}$ is the volumetric correction, which on average is $0.9 ; \mathrm{k}$, is the $\mathrm{k}^{\text {th }}$ node along $z$ direction; $n^{\text {end }}$ is the last node of the numerical domain along $z$ direction.

The total amount of melt extracted is converted into extrusive and intrusive igneous rocks:

$$
\left\{\begin{array}{l}
V o l_{\text {eff }}=\left(1-I_{R}\right) V_{\text {ext }}^{\text {Tot }} \\
\operatorname{Vol}_{\text {int }}=\left(I_{R}\right) V_{\text {ext }}^{T o t}
\end{array}\right.
$$

Where $V_{o l} l_{e f f}$ and $V_{\text {Int }}$ is the extruded (effusive) and intruded volume, respectively. $\mathrm{I}_{R}$ represents the volumetric amount of intrusion with respect to the total volume of melt extracted. The effusive volcanic rocks are treated as if they were sediments: $\operatorname{Vol}_{e f f}$ is converted into an effective thickness dividing it for the current finite difference cell area, then is used to shift the (internal) free surface (see Fig. S1).

The intrusions are emplaced in a specific area of the crust (see Fig.1) (Wallner \& Schmeling (2016)), the size and location of which depends on the current crustal thickness:

$$
\left\{\begin{array}{l}
v_{\text {int }}=\left(\frac{V_{\text {Int }}}{D_{\text {Min }}-D_{\text {Max }}}\right) d z \\
D_{\text {Min/Max }}=Z_{\text {Moho }}+\left(D_{\text {Int }} \pm D_{\text {Tol }}\right) \delta_{\text {crust }}
\end{array}\right.
$$


Where $D_{M i n}$ and $D_{\text {Max }}$ are the minimum and maximum depth of the intrusion interval, $D_{\text {Int }}$ is the depth of intrusion and $D_{T o l}$ is the relative dimension of half of the intrusion interval (which is an input parameter). $\delta_{c r u s t}$ and $Z_{M o h o}$ are the thickness of the crust and Moho depth at a given $x$ and $y$ coordinates. The volumetric source term used in the eq. 1 are computed by assembling a melt contribution to each rock type:

$$
\mathbf{S}=\frac{1}{d t}\left(1-\frac{d V}{d V-V_{\text {ext }}}\right)+\frac{1}{d t}\left(1-\frac{d V}{d V+v_{\text {int }}}\right)
$$

The source term is computed assuming that that extraction and injection locally shrink or expand the control volume during the timestep. It is an effective volumetric deformation $(1 / s)$.

\subsubsection{Petrological Modeling}

Each marker is associated with a rock-type that is linked to a calculated phase diagram showing the equilibrium mineral assemblage and melt proportion as a function of $P$ and $T$ conditions, and the rock's thermo-mechanical properties. The rock type of each marker can change as a function of the total melt extracted. Every time that the phase diagram is changed, the amount of radiogenic heat is reduced by a factor of 2 (see Tab. S2). The phase diagrams store the melt quantity and the density of the solid fraction while the density of the melt is assumed constant (2700 and $2400 \mathrm{kgm}^{-3}$ for mantle and mafic phase diagrams respectively). Felsic crust formed as a consequence of crystallized TTGs magmas is modeled as a passive phase with fixed density $\left(2700 \mathrm{kgm}^{-3}\right)$, and it is not associated with any phase diagram.

The rock-types are divided into two sets: 1) mantle (Ml); 2) mafic crust $(M C)$ (as in (Piccolo et al., 2019)):

1. Mantle phase diagrams represent six different steps of mantle depletion $(M D 0 \%, M D 10 \%, M D 20 \%, M D 30 \%$, MD40\% and MD50\%) and were computed using Perple_X (Connolly, 2009). We used the activity-composition model of Jennings \& Holland (2015), and all calculations assume a buffered oxygen fugacity (all the compositions are listed in Tab.1, all phase diagrams are shown in Fig. S2). The first step of depletion (Mantle Step $0 \%$ ) is modeled using the pyrolite composition from McDonough \& Sun (1995). The chemical evolution is assumed to be only a function of the amount of extracted melt. We compute the depleted phase diagrams using the average composition of the residuum along the $10 \%$ melt isoline in every phase diagram (e.g. $M D 10 \%$ is computed using the residuum of the $M D 0 \%, M D 20 \%$ is computed using the residuum composition of $M D 10 \%$, etc.).

2. Mafic phase diagrams represents four depletion steps (BSO\%, BS15\%, BS30\% and BS45\%) (see Fig. S2). All phase diagrams were computed using THERMOCALC 3.45 (Powell \& Holland, 1988), using the Holland \& Powell (2011) dataset (ds62). The starting phase diagram has the composition of a typical enriched Archean basalt (EAT). All solution model ( $a-x$ relations) used to produce these phase diagram are: epidote, olivine (Holland \& Powell, 2011), silicate melt, augite, hornblende (Green et al., 2016), garnet, orthopyroxene, biotite, chlorite (White et al., 2014), magnetite-spinel (White et al., 2002), ilmenite-hematite (White et al., 2000), Cbar-1 plagioclase, K-feldspar (Holland \& Powell, 2003), and muscovite-paragonite (White et al., 2014).

Melt extracted from the mantle is converted into anhydrous intrusions and extruded hydrated EAT (BS0\%). We assume that effusive rocks are always hydrated, consistent with the inferred Archean sub-marine environment (Kump \& Barley, 2007).

Mafic phases are represented by five rock-types: $B S 0 \%, B S 15 \%, B S 30 \%, B S 45 \%$ and anhydrous intrusive mafic crust, where $B S 0 \%$ is the protolithic metabasalt composition. $B S 0 \%$ is assumed to be fully hydrated, and that the molar volume of water is sufficient to minimally saturate the solidus at $1.0 \mathrm{GPa}$ (Palin et al., 2016a). After $15 \%$ of melting and melt extraction, the rock type is changed to the next basaltic step (e.g. BS15\%). BS45\% is most depleted lithotype and has the same composition of BS30\% but is no longer able to produce melt. The mafic intrusions are assumed to be anhydrous, and unable to produce any melt, and are modeled as if they had the same composition of BS45\% (as in (Piccolo et al., 2019)). They represent the composite underplated bodies expected to be found at the base of an evolving oceanic plateau (Palin \& Dyck, 2018; Van Kranendonk, 2010; Cox, 1980). All the melt that is extracted from the mafic protolith is converted into felsic crust. We do not distinguish any subtype of felsic rocks, and we do not consider the felsic rocks to produce any subsequent melts.

\section{Results}

We focus on the effect of the melt extraction parameter of the mantle phases and the asthenospheric mantle potential temperature $\left(\mathrm{T}_{P}\right)$. We carried out both $2 \mathrm{D}$ and 3D numerical experiments. 3D numerical experiments have been 
performed to explore the effect of $\mathrm{T}_{P}$ while 2D numerical experiments have been performed to test the effect of $\mathrm{dM}$ and $\mathrm{M}^{\text {trs }}$, and the long-term evolution of the system.

We mainly focus on the $P$ and/or $T$ conditions at which both felsic and mafic melts are extracted because this information can be used as a compositional proxy. We classify the felsic melts extracted into two main categories: TTG-like melts (TTG-opt) and non-TTG-like melts. TTG-like melts are the melts extracted within a $P-T$ range that produces a bulk composition that best fits the chemistry of the natural TTG (TTG-opt). We further split TTG-like melts into three categories following Moyen (2011) as a function of the pressure of extraction within the optimum field: low-pressure TTGs (LP-TTG, $0.6-1.0 \mathrm{GPa}, 800-1000{ }^{\circ} \mathrm{C}$ ), medium-pressure TTGs (MP-TTG, $1.0-1.8 \mathrm{GPa}, 800-1000{ }^{\circ} \mathrm{C}$ ) and high-pressure TTGs (HP-TTGs, $>1.8 \mathrm{GPa}, 800-1000^{\circ} \mathrm{C}$ ). Non-TTG-like melts are all other felsic melts of a broadly granitic composition that did not form in the optimal P-T field identified above. Mafic melts are tracked using their extraction temperature, which can give insights on mantle source (plume or asthenosphere or contaminated mantle).

In order to describe the macroscopic structural features, we introduce the following terminology: external zone represents the initial lithosphere (sometimes referred as old-lithosphere); internal zone is the newly produced composite crust produced during the plume-lithosphere interaction and affected by RTIs; boundary zone is the limit between internal and external zone, dominated by the delamination of the lower crust of the external zone.

Although they are both driven by buoyancy, we differentiate delamination and RTIs, as both have different surface manifestations and deformation patterns. Delamination processes are associated with peeling off of the dense lower crust -they produce asymmetrical topography and stress pattern (compressive in the direction of propagation and extensional in the opposite direction) Gögüuss \& Ueda (2018); Beall et al. (2017); Le Pourhiet et al. (2006); Morency \& Doin (2004). By contrast, RTIs are symmetric and characterized by compressive and subsequent extensional tectonics after the removal of the dense unstable portion of the crust/lithosphere Beall et al. (2017); Molnar et al. (1998). We further differentiate the thinning processes into two categories: gravitational thinning is related with RTIs instabilities, and imply that the removal of mass from the crust is not compensated by the production of new crust; syn-magmatic thinning is associated with the asthenosphere drag forces.

\subsection{Initial Setup}

We performed systematic experiments in 2D and 3D. The 2D numerical setups are boxes whose $y$ axis is $2 \mathrm{~km}$ ( 3 grid nodes) compared with 100's of $\mathrm{km}$ for the $x$ and $z$ directions. All numerical experiments shares the same boundary conditions being:

- Mechanical: free slip on all boundaries except for the top boundary, which features an internal free surface with a stress free open top boundary;

- Thermal: the top and bottom faces are isothermal, while the lateral boundaries have no flux boundary conditions. The top boundary temperature is $20^{\circ} \mathrm{C}$, while the bottom boundary temperatures are set to be $1700^{\circ} \mathrm{C}$ in most of the experiments exploring low $T_{P}$ scenarios, while the high $T_{P}$ scenarios has a lower bottom temperature in agreement with the adiabatic gradient;

The 2D numerical domain size is $1000 \times 2 \times 520 \mathrm{~km}$ with $257 \times 3 \times 257$ nodes (along $x, y$ and $z$ directions respectively), while the 3D numerical setup is $800 \times 800 \times 520 \mathrm{~km}$ in size with $257 \times 257 \times 257$ nodes. The air layer is $20 \mathrm{~km}$ thick in all cases (see Fig.S4).

The initial compositional field features $100 \mathrm{~km}$ thick lithosphere, divided into $30 \mathrm{~km}$ of mafic crust and $70 \mathrm{~km}$ of depleted harzburgite $(M D 30 \%)$. The ratio between crust and lithospheric mantle is constant in all the numerical experiments. The upper crust is composed of hydrous basalts (BSO\%), which thickness is $15 \mathrm{~km}$ while the lower crust is made up of dry and infertile mafic intrusions. The asthenosphere is composed of pyrolytic and fertile mantle McDonough \& Sun (1995) (MD0\%). The plume head is thermal and placed at the centre of the model and has a radius that is varied from 150 to $200 \mathrm{~km}$. Mantle lithologies are modelled with a dry olivine rheology flow law (Hirth \& Kohlstedt, 2004). The hydrous mafic and the felsic crust are modelled with wet quartzite flow law, while the residual mafic composition (BS45\%) and dry intrusions have a mafic granulite rheology (Ranalli, 1995). All geological units have the same initial friction angle $\left(30^{\circ}\right)$ and cohesions $(10 \mathrm{MPa})$. The cohesion and friction angle varies linearly as function of the accumulated plastic deformation until they reach $30 \%$ of their original values.

All references scenarios assume that mantle intrusive/effusive ratio $\left(\mathrm{I}_{R}\right)$ is 0.6 , consistent with plume geodynamic estimates (Crisp, 1984; White et al., 2006). The interval of intrusions of the melt produced by mantle lithologies is between the Moho depth and 0.6 of the total thickness of the crust. The felsic melt produced by mafic crust is all converted into felsic intrusion $\left(I_{R}=1\right)$, with an interval of intrusion spanning $0.5-0.9$ of the total crustal thickness. 
The $\mathrm{T}_{P}$ temperature of the experiments range from $1350^{\circ} \mathrm{C}$ to $1550{ }^{\circ} \mathrm{C}$, while the potential temperature of the plume is kept constant at $1600^{\circ} \mathrm{C}\left(T^{P l}\right)$. In all the experiments the adiabatic gradient is $0.4^{\circ} \mathrm{C} / \mathrm{km}$. For the lower $T_{P}$ experiments $\left(<1500^{\circ} \mathrm{C}\right)$, we assumed that the temperature of the lower boundary is higher than the value expected for the given $T_{P}$ to increases the convective vigors. The initial geothermal gradient of the lithosphere is a linear double stage geotherm, featuring a $\mathrm{T}_{M o h o}$ of $800{ }^{\circ} \mathrm{C}$ and a temperature at the base of the lithosphere that depends on the asthenospheric $\mathrm{T}_{P}$.

\subsection{Effect of $\mathbf{d M}$ and $\mathrm{M}^{\text {trs }}$}

It is possible to subdivide the experiments into two regimes: low melt extraction efficiency $(\mathrm{d} M<0.01)$ and high melt extraction efficiency ( $\mathrm{dM}>=0.01)$. We briefly show two representative experiments that describe the geodynamic evolution of the two regimes.

\section{Low melt extraction efficiency $\left(\mathrm{dM}=0.001, \mathrm{M}^{\text {trs }}=0.001, \mathrm{~T}^{P l}=1600{ }^{\circ} \mathrm{C}, \mathbf{R}=200 \mathrm{~km}, \mathrm{~T}_{P}=1600{ }^{\circ} \mathrm{C}\right)$}

1st Stage: Plume arrival stage (see Fig. 2) During the initial stage, the plume starts ascending and forces upper mantle convection (see Fig. 2, 0.881 Myrs). The mantle upwelling erodes the lithosphere and induces the partial melting of the asthenosphere underneath it. The positive buoyancy of the partially molten asthenosphere increases due the low $d M$ (see Fig. 2, 0.881 Myrs, column b), allowing the asthenosphere to penetrate the lowermost portion of the lithospheric mantle.

After the plume arrives at the base of the lithosphere, it spreads along the $x$ direction (see Fig. 2, 2.169 Myrs). During the spreading, mantle plume diapirs penetrate the lithospheric mantle. These diapirs have a mushroom shape and their peripheral portions are composed of residual mantle. This results in the generation of small magmatically thickened areas (50-100 km scale), that imposes a wavelength on the crustal thickness. The flux of mafic melts is insufficient to heat up the hydrated crust, so no felsic crust is produced. As a consequence of localized crustal thickening, the lower crust starts to be eclogitized, producing a negative and unstable volume of mafic crust (see Fig. 2 2.169 Myrs, column b).

2nd Stage: Syn-magmatic extension and lithosphere removal (see Fig 2, 2.765-2.813 Myrs). The eclogitized lower crust drips off, removing the lithospheric mantle and causing the return flow of the astenosphere. The asthenospheric return flow induces the production of high volume of mantle melt. The positive buoyancy of the partially molten mantle increases, producing an active upwelling (see Fig 2, 2.765 Myrs, column b). The asthenosphere comes in contact with the hydrated crust, causing the production of significant volumes of felsic melt. The partially molten mantle spreads beneath the crust and its drag force initiates syn-magmatic extension. The newly produced crust is thin in the central area of the upwelling and tends to thicken laterally. Then after the removal of the all unstable portion of the lower crust, the upwelling is localized at the centre of the numerical domain (see Fig 2, 2.765 Myrs, column b). Three distinct structural homogeneous area are generated: the internal zone represents the area initially affected by the plume that expands laterally and is characterized by a fast syn-magmatic extension; two boundary zones, which are mechanically thickened areas and characterized by the constant peeling off of the lower crust (see Fig 2, 2.765 Myrs, column b); and two external zones that are forced to under-thrust the new composite crust. At the end of the stage, the gravitational instabilities are still active and are mainly RTIs. This final process allows further mantle melting which produces new hydrated basalts that bury the felsic crust.

3rd stage: Quiescent stage (see Fig 2,14.180 Myrs). After the removal of the old lithosphere, the simulation enters in the quiescent stage. A new compositional lithospheric mantle stabilizes and the production of new crust is limited. Felsic crust is located at Moho boundary because of its burial and as a consequence of the removal of the lower residual and intrusive mafic crust (see Fig 2, 14.180 Myrs, d).

\section{High melt extraction efficiency $\left(\mathrm{dM}=0.05, \mathrm{M}^{t r s}=0.001, \mathrm{~T}^{P l}=1600{ }^{\circ} \mathrm{C}, \mathbf{R}=200 \mathrm{~km}, \mathrm{~T}_{P}=1600{ }^{\circ} \mathrm{C}\right)$}

1st stage: Plume arrival (see Fig. 3, 1.962 Myrs): During plume ascent, the lithospheric mantle is stable. During the spreading of the mantle plume beneath the lithosphere, most of the melt is extracted in the plume axis area generating a oceanic plateau that extends from -200 to $200 \mathrm{~km}$ (see Figure 3, 1.962 Myrs column a). The lower crust of the thickened plateau becomes unstable (see Figure 3, 1.962 Myrs column b), and the hydrated crust starts melting producing small volume of felsic melts. The production of felsic melts and their extraction produces a considerable volume of residual mafic crust, that enhances the buoyancy contrast with the underlying and mantle.

2nd stage: Dripping, delamination and lithospheric mantle removal (see Figure 3,2.062-3.207 Myrs). Due to the continuous magmatic activity the lower crust of the oceanic plateau drips off. The dripped lower crust locally removes the lithospheric mantle, causing an asthenosphere return flow. The ascending astenosphere partially melts and enhances the production of new mafic intrusions, that heat up the hydrated crust allowing the production of further 
felsic melts (see Figure 3, 1.962 Myrs column a and b). The dripped off material interrupts the plume buoyancy flux and the normal asthenosphere replaces the removed mantle lithosphere. The oceanic plateau undergoes syn-magmatic extensions and gravitational thinning (see Figure 3, 2.186 Myrs). After the complete removal of the lower crust of the oceanic plateau, it is possible to identify internal, external and boundary zones. The internal zone is dominated by RTIs that thins the crust. The boundary zones are characterized by the discontinuous delamination of the lower crust. Delamination and RTIs assist the expansion of the internal zone until the external zone is completely removed.

3rd stage: Quiescent (see Figure 3, 14.180 Myrs). After the removal of the old lithosphere the simulation enters its quiescent stage. The amount of new felsic crust produced is small compared to the previous stages. Most of the felsic crust is buried to middle and lower crustal depths due to the addition of new hydrated basalt during the removal stage (see Figure 3,14.180 Myrs column d). Due to the RTIs, the amount of felsic crust is not evenly distributed in the section, and the local felsic crust anomalies generate small domes similar to the dome-and-keel geometry.

We performed nine 2D numerical experiments in order to constrain the effects of $\mathrm{dM}$ and $\mathrm{M}^{\text {trs }}$ of the mantle phases. Although $\mathrm{M}_{\text {trs }}$ controls the melt extraction and the volumetric melt fraction that is retained in the source, it has no effects on the geodynamic evolution nor on the absolute volume of the felsic and mafic crust. dM exerts a strong control on the volume of extracted melts and on the geodynamic evolution of the system. To perform 3D numerical experiments, we choose to use the parameters of the high $d M$ numerical experiments.

\subsection{Effect of the potential temperature of the asthenosphere}

We explore the effect of the $\mathrm{T}_{P}$ of the asthenosphere using 3D (run for 10 Myrs) and 2D (run for 40 Myrs) numerical experiments. Our results can be divided into two main regimes: high mantle potential temperature (high $\left.\mathrm{T}_{P}\right)$ and low mantle potential temperature regimes (low $T_{P}$ ).

\subsubsection{High mantle potential regimes $\left(\mathrm{T}_{P}>=1500^{\circ} \mathrm{C}\right)$}

Reference experiment high potential temperature regime $\left(\mathrm{dM}=0.05, \mathbf{M}^{t r s}, \mathbf{T}^{P l}=1600{ }^{\circ} \mathrm{C}, \mathbf{R}=200 \mathrm{~km}, \mathbf{T}_{P}\right.$ $=1500{ }^{\circ} \mathrm{C}$ )

1st stage: Plume Arrival (see Fig. 4, $1.308 \mathrm{Myrs}$ ): As soon as the mantle plume approaches sub-lithospheric depths $(200-150 \mathrm{~km})$, it starts to produce melts. The spreading velocity of the mantle plume is limited $(\sim 20 \mathrm{~cm} / \mathrm{yrs})$, forcing the melt extraction processes to occurs in a limited circular area. The first drip occurs soon after the penetration of the plume into the bottom lithospheric mantle, while, ongoing mafic magma intrusion and extrusion results in magmatic thickening of the crust. Most of the TTG-like melts are produced at medium pressure condition (1.0-1.8 $\mathrm{GPa}$ ). After the occurrence of the first RTIs the extraction of MP-TTG like melts is focused on the boundary zone, while the internal zone is dominated by the extraction of low pressure felsic melt (see Fig. 4, 1.308 Myrs, column b).

2nd stage: Dripping, delamination and lithospheric removal (see Fig. 4, 2.108-2.593 Myrs): After the delamination of the first drip, the internal zone radially extends. In the internal zone, new felsic and mafic crust is continuously produced causing RTIs, while in the boundary zone the lower crust of the external zone is removed via delamination (see Fig. 4, 2.108 Myrs column a). The delamination of the lower crust has two effects: 1) it allows a syn-magmatic extension in the internal zone allowing its expansion; and, 2) it deforms the crust of the external zone. The delamination drives a burial of the hydrated mafic crust, resulting in the production of LP-MP-HP TTG like melts from the external to internal zones(see Fig. 4, 2.108 Myrs column b). The internal zone is characterized by the continuous extraction of LP-TTG melts, with some spots of MP-TTG melts associated with crustal drip. The internal zone is gravitationally thinned. The generation of residual mantle generates a stable density profile beneath the new composite crust. This regime is not stable, because as soon as the internal zone reaches a radius of $100-150 \mathrm{~km}$, the delaminated crust in the boundary zones segments in a discrete slab, and during their foundering they become similar to a RTIs (see Fig. 4, 2.362 Myrs column a/c ). The transition from slab-like to drip-like gravitational instabilities induces a significant removal of the lithospheric mantle resulting in a syn-magmatic thinning of the crust. The removal of the lithospheric mantle triggers mantle melting beneath the external zone which results in the production of high volumes of LP-TTG melts and in the weakening of the crust (see Fig. 4, 2.362 Myrs column a-b-c). The delamination/drip processes become extremely efficient and the boundary zone is destroyed. The outward propagation of the internal zone happens at high speed $(\sim 100 \mathrm{~cm} / \mathrm{yr})$ and the remnants of the boundary zone propagate radially and then they are removed by RTIs (see Fig. 4, 2.593 Myrs column a). The interference between different RTIs generates local felsic crust anomalies.

3rd stage: Quiescent (see Fig. 4, 8.301 Myrs column a): After the removal of the old lithosphere, the experiment enters in its final stage. The newly-generated crust is mostly composed of mafic components $(\sim 40 \% \bar{F})$ (see Fig. 5, d). However, the felsic intrusive bodies are not homogeneously distributed within the crust (see Fig 4 a-b-d). These felsic bodies are irregular and are surrounded by mafic crust. The felsic crust anomalies are correlated with positive 
topographic ones, while the area composed of mafic lithologies are associated with negative topographic anomalies (see Fig 4 c). Since the numerical experiments runs only for 10 Myrs, we do not observe directly the partial convective overturn. However, the architecture of the new crust and the spatial distribution of the felsic components within its volume, predispose the occurrence of partial convective overturn.

During the evolution of the experiment significant volumes of mafic melt are extracted from the asthenosphere and only a minor part from the plume (see Fig 5 column b). The temperature at which the mafic melts are extracted varies from a maximum imposed by the potential temperature of the plume to a temperature lower than the initial background asthenospheric $T_{P}\left(\sim-100^{\circ} \mathrm{C}\right)$. $\mathrm{T}^{\text {Gen }}$ (temperature of generation) of the mafic melts. The distribution of the temperature of extraction varies with time with the initial stage of experiments featuring a wider distribution of $\mathrm{T}^{G e n}$ compared to the quiescent stage. The variability of the mafic $\mathrm{T}^{G e n}$ is related to the cooling of the mantle and suggests a strong interaction between cold crustal material and asthenosphere. The mafic growth curve (cumulative volume of mafic melts extracted vs time, $P^{M a f i c}$ ) show an initial slow production rate followed by an exponential production rate increase during the removal stage.

The felsic crust growth curve (cumulative volume of felsic melts extracted vs time, $P^{F e l s i c}$ ) has the same shape of the mafic growth one (see Fig 6 column a) suggesting a strong relation between mafic and felsic melts production. The volumetric fraction of TTG-like melts (TTG-opt) varies with time. Nevertheless, most of the felsic melts produced are extracted outside the optimum field at lower pressure and temperature (see Tab. S3). The proportion of LP, MP and HP TTG like melts changes with time, with an initial stage featuring significant volumetric fraction of MP-TTG like melts, which decreases with time during the dripping stage. The gravitational thinning associated with RTIs within the internal zone favour the production of LP-TTG (see Fig 4). The destruction of the boundary zone prevents an efficient burial of the mafic hydrated basalt to great depth.

The experiment featuring higher mantle potential temperature $\left(T_{P}=1550^{\circ} \mathrm{C}\right)$ shows the same evolution (see Fig 6). The only difference that can be reported is related to the absolute quantity of new crust which is higher than the reference scenarios. We additionally tested the effect of changing the interval and the relative depth at which the mafic intrusions are emplaced. The main geodynamic scenario is not changing but the pressure at which felsic melts are extracted is higher than the reference scenarios resulting in larger amounts of TTG-like and MP-TTG-like melts. $\mathrm{D}_{T o l}$ (the thickness of the intrusion interval normalized over the current crustal thickness) exerts a second order control on the condition at which TTG-like melts are produced (see Fig 6 column a), while the $\mathrm{D}_{\text {int }}$ has a primary role, promoting the extraction of MP and HP TTG-like melts.

The 2D experiment (see Fig 3) shows first-order similarities with the 3D numerical experiment, but there are some important differences to highlight (see Fig 4 column a). The first main difference is related to the fact that the boundary zone in the 2D experiments is not destroyed during the removal stage. The second difference is related to the volumetric fraction of TTG-like melts produced and volumetric fraction of MP-HP TTG like melts, which are higher in $2 \mathrm{D}$ scenarios.

\subsubsection{Low mantle potential temperature regime}

\section{Reference experiment low potential temperature regime $\left(\mathrm{dM}=0.05, M^{t r s}, \mathbf{T}^{P l}=1600{ }^{\circ} \mathrm{C}, \mathbf{R}=200 \mathrm{~km}, \mathbf{T}_{P}=\right.$ $\left.1400{ }^{\circ} \mathrm{C}\right)$}

1st stage: Plume arrival (Fig. Fig 7, 0.560 Myrs ): The first stage of the experiment is similar to the high potential temperature reference experiment. The only difference is related to the efficiency of mantle plume spreading beneath the mantle lithosphere. It is possible to observe the same pattern of felsic melt extraction, with a more prominent extraction of LP-TTG like melts within the internal zone and the extraction of higher pressure melts in the boundary zone.

2nd stage: Delamination and sub accretion (Fig. 7, 1.139-8.524 Myrs): After the occurrence of the first RTIs, it is possible to recognize the internal, boundary and external zones. The internal zone expands thanks to the delamination of the lower crust of the external zone, and it gravitationally thins due to the RTIs (Fig. 7, 1.139 Myrs column a). The felsic crust produced within the internal zone is drifted apart towards the boundary zone, because of drag forces exerted by the astenospheric return flow. The main effect is promoting the extraction of LP-TTG in the internal zone and crustal thickening in the boundary zone (and thus MP TTG like extraction ) (Fig. 7, a-c). The boundary zone maturates as a function of the amount of the felsic crust that is accreted at the rim of the internal zone (see Fig. 7, 3.395 Myrs), which additionally facilitates the external zone sub-accretion. The result of the maturation of the boundary zone is to create an annular felsic terrain and forebasin. The pressure of felsic melt extraction within the external zone increases towards the internal zone mimicking a subduction-like process (see Fig.7 b). 
The experiment does not reach the quiescent stage (Fig 7, 8.524 Myrs). And the processes described above stabilize the boundary zone generating a plate-like boundary feature. At the end of the time span explored, the crust can be subdivided into three areas: the internal zone whose crust is mostly mafic with felsic intrusive bodies that are emerging locally due to the RTIs (see Fig. 9, a, b d); an annular continental terrain at the rim of the internal zone over-thrusting the external zone crust; a annular foreland basin whose depth is $-1.0 \mathrm{~km}$ (Fig.9 c). The annular felsic terrains have a topography that spans from $2.0-3.0 \mathrm{~km}$ (Fig.9 c) and internal zone featuring a relative high topography $(0.6-1.5 \mathrm{~km})$. The topographic gradient imposed by the annular felsic terrain is high and facilitates the over-thrusting of the external zone mafic crust due to the gradient of gravitational potential energy between the annular felsic terranes and fore-land basin (similar to the results of Rey et al. (2014)). In the internal zone the topographic heights are associated with the amount of felsic crust, and the pattern of small basins is like those that have been observed in the reference high $T_{P}$ scenarios (Fig.9 c-d).

The amount of new mafic crust generated increases linearly with time (see Fig 10, column b, first row) and $\mathrm{T}^{\text {Gen }}$ of the mafic melts varies from the mantle potential temperature to a temperature lower than the initial asthenospheric $\mathrm{T}_{P}$. The variability of the mafic melt extraction temperature decreases with time indicating a progressive cooling of the asthenosphere due to the continuous delamination/RTI processes.

The volumetric fraction of TTG-like melts is higher than high $T_{P}$ experiments, and the proportion of LP-MP-HP TTG like melts is variable. The volumetric fraction of LP TTG-like melts decreases with time, while the MP and HP TTG like melts proportion increases (see Fig 10, column a, first row). The decrease of LP-TTG like melts is a consequence of the stabilization of the boundary zone.

A higher initial $T_{P}\left(1450{ }^{\circ} \mathrm{C}\right)$ does not change the main geodynamic processes but allow a faster propagation of the internal zone. Therefore, the internal zone reaches the boundary of the numerical domain, generating similar processes to those in the high $T_{P}$ experiments. However, in this case, rather than being a physical transition, it is a numerical artifact that is a consequence of the limited size of the numerical domain. The removal of the old lithosphere can be observed in both mafic and felsic growth curves, because they shift from linear to exponential growth rate (see Fig 10 a,b, second row). Lowering the initial mantle potential temperature $\left(1350{ }^{\circ} \mathrm{C}\right)$ results in a twofold decrease in the volume of both mafic and felsic crust respect with the low $T_{P}$ reference scenario. The volumetric fraction of TTG-like melts is low, and the proportion of HP and MP TTG melts are low. Decreasing the initial thickness of the lithosphere does not affect the previous results but reduces the proportion of MP and HP TTG-like melts and is associated with a higher production of felsic and mafic melts.

We tested the same setup using a 2D numerical experiment. The main difference is related to the volumetric fraction of TTG-opt, which is higher. LP TTG like melts are the most common type of melt at low $T_{P}$, this result is in stark contrast with the high $T_{P}$ one. We performed additional low $T_{P}$ experiments to observe the long term effect of the thermal boundary condition and radiogenic heating and initial lithospheric thickness (see Fig. S6). Lowering only the thickness and the temperature at the base of the numerical domain yields a two-stage experiment, in which the expansion of the internal zone slows down with time and shuts down for 3-4 Myrs (see Fig S6 and S7). However, due to the high radiogenic heat production, the mantle heats up with time producing a new magmatic pulse that results in the expansion of the internal zone. If all mantle rocks feature a low radiogenic heat productivity (similar to the Phanerozoic one, $A=0.3310^{-5} \mathrm{~W} / \mathrm{kg}$ ) the outward expansion of the internal zone stops, and the experiments remains in a quiescent stage.

\subsubsection{Difference between 2D and 3D numerical experiments}

The 2D and 3D numerical experiments have important differences primarily related to the production of felsic crust, which is extracted at low pressure in 3D numerical experiments in contrast with higher pressures in the 2D experiments. These differences emerge because of the RTIs are more developed in 3D cases than in 2D numerical experiments. The differences arise from the limited spreading velocity of any 3D upwellings (see Fig 11). The spreading velocity (the $\mathrm{x}$ and $\mathrm{y}$ velocity components of velocity) controls the distribution of the new crust, which results in anomalous localizations of crustal thickness. The spreading velocity beneath the lithosphere depends on the temperature contrast between normal asthenosphere and the plume. In the $2 \mathrm{D}$ numerical experiments, the lateral spreading velocity of the plume is higher than in 3D, allowing generation of a thickened and wider oceanic plateau: this promotes melting of hydrated crust at moderate pressure, and generates a more stable configuration. In $2 \mathrm{D}$ cases featuring a lower asthenosphere $T_{P}$, a thinner oceanic plateau is formed that promotes LP TTG generation. In 3D cases, most of the mafic-melts are extracted along the plume axis direction, yielding an ultra-thickened and narrow plateau, which is more unstable with stronger RTIs resulting in a more efficient gravitational thinning. 
A PREPRINT - FridAY $21^{\text {ST }}$ MAY, 2021

\section{Discussion}

\subsection{Limitations}

The resolution of the numerical experiments can affect the geodynamic evolution and the estimates of the felsic/mafic crust produced. We performed the 2D numerical experiment shown in Fig. 3 with different grid sizes (see Tab S4) to assess the impact of variable resolution; however, the key geodynamic processes do not show any significant differences. The most obvious change is related to the size of RTIs, which depends on the ability of the code to resolve the crust. The numerical resolution seems to not affect the total volume of mafic crust and the final crustal thickness at the end of the experiments. The normalized total mafic productivities of all simulations with respect to the average spans from -0.04 to $0.06\left(\sim \pm 13 \cdot 10^{3} \mathrm{~km}^{3}\right)$. The final crust thickness shows similar variability, decreasing with resolution and ranging from -0.08 (high resolution) to 0.08 (low resolution) $(\sim \pm 1.5 \mathrm{~km})$. The quantity that is most affected is the absolute volume of felsic crust produced, which increases with the resolution. But instead of being caused by the resolution dependency of our melt extraction algorithm, it is still associated with the resolution of the crust. The volume of felsic crust and volumetric fraction of TTG-like melts increase with the resolution. The relative proportion of each LP, MP and HP is also affected, with MP-TTG becoming dominant at extremely high resolution (i.e. 513x513 nodes per direction), largely at the expense of LP-TTG like melts and minorly at the expense of HP-TTG like melts. Nevertheless, the distribution of the $P-T$ conditions are consistent within these numerical experiments (see Fig. S8). Our results still hold at low and high resolution, although, it is necessary to consider the uncertainty introduced by the numerical resolution.

Most of the numerical simulations enter a quiescent stage. This stage is influenced by the size of the numerical box and by the mantle melt productivity, so it can be interpreted as a saturation stage. Despite this limitation, they key physical processes are not affected.

Our initial scenario depicts a thermal (small) tail-less plume. This plume is not fed by any buoyancy flux coming from the lower mantle. This is done to model a plume in stagnant lid convection mode, in which long lived plumes are unlikely to happen. At the end of the numerical experiments the crustal thickness is thin $(\sim 28 \mathrm{~km})$ with respect to the inferred scenarios ( $35-50 \mathrm{~km}$ ) (Van Kranendonk et al., 2015; Van Kranendonk, 2010; Smithies et al., 2009) and most likely a long-lasting mantle plume would yield a thicker crust. However, most of the thinning processes are associated with gravitational instabilities, that in case of a long-lasting plume are expected to be more effective.

We introduce a novel approach to deal with the compositional variation due to magmatic processes; however, it introduces several issues, such as stepwise variations of properties. The stepwise variations of density are reduced by the interpolation scheme employed and their effect is minor compared to the actual phase reactions observed within the same diagram. Radiogenic heat production is handled discretely by decreasing its value as a function of the depletion step. This may affect the long-term results of our numerical simulation, which (together with the extremely high computational cost of each simulations) is one of the reasons that we opt for short-term experiments. The most suitable way to handle radiogenic heat production is to enforce a partition coefficient of radionuclides as a function of the melt produced. In order to do that, it is necessary to assume a partition coefficient on the fly as a function of mineralogical composition (e.g. Rummel et al. (2018)) which is computationally unfeasible. Moreover, we assume that the average composition of the residuum along a melt isoline is representative of all the chemical complexity. The last limitations is associated with the usage of the phase diagrams. We assume that the thermodynamic equilibrium is always reached and we neglect the effects of metastability and the kinetic of reactions that can control the timescales of the processes.

\subsection{Mafic crust production}

The primary mafic melt composition depends on the thermal state of the mantle. Consequently, the basalts that feature a composition close to the primary melts have been widely employed to estimate Archean mantle $\mathrm{T}_{P}$ (Ganne \& Feng, 2017; Herzberg et al., 2010). The debate concerning the Archean upper mantle potential temperature is still open with estimates spanning from 1400 to $1650{ }^{\circ} \mathrm{C}$ (Aulbach \& Arndt, 2019; Herzberg et al., 2010). Moreover, these estimates show considerable variations at any one point in time (Ganne \& Feng, 2017; Herzberg et al., 2010) suggesting that this variability may be due to the interaction of a relatively cold asthenosphere and mantle plumes (Kamber, 2015; Arndt, 2013). Our results suggest that the mafic crust composition can be variable with high and low \#Mg mafic rocks coexisting consistently with many Archean terranes such as Pilbara or Kapavaal (Van Kranendonk et al., 2015).

The temperature of extraction of mafic melt is variable at any timestep. The colder mafic melts indicate a strong interaction with the delaminated crust. Although we do not consider chemical exchange, degassing and magmatic hybridization in our simulations, this thermal exchange must result in at least one of these processes (Bédard, 2006). The mantle may be hydrated and contaminated by the dripped crustal material. These processes are feasible and 
could modify the composition of the mafic melt opening new perspectives for TTGs petrogenesis. For instance, hybridization between mantle and crustal related melts has been invoked to produce the mafic source of East Pilbara TTGs (Smithies et al., 2009). If the mantle is sufficiently hydrated, the mafic intrusions can carry enough water to yield TTG-like melts during fractional crystallization or subsequent partial melting events Smithies et al. (2019); Van Kranendonk et al. (2015); Macpherson et al. (2006). Despite the fact that our simplified approach cannot reproduce all these processes of contamination, our results indicate that they are possible and need to be explored in a consistent geodynamic and petrological way.

\subsection{Felsic crust production}

Most of the felsic melts are extracted outside the optimum field for TTG petrogenesis with significant differences between 2D and 3D experiments: 2D experiments generally show a higher proportion of TTG-like melts (40-50\%) with respect to $3 \mathrm{D}(20-30 \%)$.

The felsic melts are mostly produced at relatively low-pressure and low-temperature conditions $\left(T^{G e n}<700^{\circ} \mathrm{C}\right)$ ensuring that most of the complementary mafic residuum is produced at low depths see Tab. S3. The production of complementary mafic residuum facilitates the gravitational instabilities (Sizova et al., 2015; Piccolo et al., 2019), and in our experiments limits the maximum thickness of the crust to $\sim 28 \mathrm{~km}$. The combination of the emplacement of mafic dry intrusions and low crustal thickness yields a thin and hot crust. In Fischer \& Gerya (2016) the dripping stage of the simulation is associated with the thinning of the crust and they observed a quiescent stage characterized by slow magmatic thickening. The dripping stage is the most productive in terms of felsic crust production, it is associated with low-pressure and low-temperature magmatism ( $\mathrm{T}<700-800^{\circ} \mathrm{C}$ and $\mathrm{P}<1.2 \mathrm{GPa}$ ), outside the TTG optimum $P-T$ field. The production of generally LP felsic melts has been identified even in global scale 2D numerical experiments (Jain et al., 2019). To promote high temperature/pressure partial melting, it is necessary to reconsider the productivity of the mafic protolith or to increase the viscosity of the crust. All the mafic crust phase diagrams stem from $B S 0 \%$, which is computed using an EAT composition, and assuming that is hydrated enough to be minimally saturated at 1.0 GPa (Palin et al., 2016a). This composition represents a likely "typical" source for the generation of felsic crust, as the degree of hydration maximizes the felsic melt generation. This saturated composition has a low wet solidus temperature close to $650{ }^{\circ} \mathrm{C}$, and it makes the mafic protolith susceptible to thermal perturbation introduced by mafic and felsic intrusive bodies. For instance, the volume of TTG-like melts increases if the depth of intrusions is close to the Moho depth and the depth interval of emplacement is narrow (see Tab. S3). Therefore, one potential solution to these issues is to consider the mafic protolith to be hydrated, but undersaturated. Lower water content shifts the temperature of the solidus to higher temperatures (Palin et al., 2016a,b), promoting high-temperature melting (within the optimum field) and may inhibit crustal-scale RTIs.

Most of the TTG-like melts are LP-TTG type, with a variable amount of MP-TTG like crust as a function of the depth of intrusion and the initial mantle potential temperature. Our results are not consistent with the world-wide TTGs data set (Moyen, 2011), firstly because we do not produce enough TTG-like melts, secondly because our TTG-like melts are dominated by LP-TTGs. However, our results are broadly consistent with the current proportion of LP and MP TTGs of the East Pilbara Paleo-Archean TTGs (Johnson et al., 2017), which is the best preserved classic dome and basin terrain developed through primarily vertical tectonic processes. The dominance of LP-TTGs in our simulations may also be a compositional artifact, as the bulk composition of the mafic protolith has not directly been addressed to produce the LP, MP and HP TTGs classification (Moyen, 2011). For instance, it has been inferred that the mafic protolith of Paleo-Archean East Pilbara TTGs are the Coucal basalts (Johnson et al., 2017; Smithies et al., 2009). These basalts have an iron-rich composition that can bear the required mineralogical assemblage to generate MP-TTGs at a lower pressure (0.7-0.8 GPa) than that proposed by Moyen (2011). In particular, all the three types of TTG melts were suggested by Johnson et al. (2017) to form at a pressure lower than 1.4 GPa. The LP, MP and HP TTGs classification reflect the occurrence of the required mineralogical assemblages and does not represent a rigid set of $P-T$ conditions. Thus, simulations that specifically aim to create the "right" proportion of LP, MP and HP TTGs in geodynamic modelling without accounting for the variability of mafic source protolith will produce misleading results. This implies that any classification is arbitrary and a more deep connection between petrological modelling and geodynamic numerical simulation is required (cf. Palin et al. (2020)).

\subsection{Structural evolution and implication for subduction initiation}

We identify two main regimes: low and high $T_{P}$. In both scenarios, with a surface dominated by mafic lithologies, which is consistent with the inferred Archean's continental crust surface (Kamber, 2010; Condie, 1993).

High $T_{P}$ regimes $\left(\geq 1500^{\circ} \mathrm{C}\right)$ We observed structures that resemble dome-and-keel geometry which has been recognized as the effect of partial convective overturn (Van Kranendonk, 2010; Van Kranendonk et al., 2004). However 
partial convective overturn occurs after a long thermal maturation of the gneiss dome due to the high radiogenic heat production (François et al., 2014; Bodorkos et al., 2006), or because of the emplacement of hot intrusions (Van Kranendonk et al., 2015). In our numerical experiments, the apparent rising of felsic domes is a consequence of RTIs and delamination induced deformation. These anomalies predispose the felsic crust to rise in the subsequent mantle-related magmatic events. The East Pilbara terrane has a long-lasting structural evolution that started during the Eo/Paleo-Archean and ended during the Meso-Archean (3.65-3.22 Ga) (Van Kranendonk et al., 2015; Hickman \& Van Kranendonk, 2012). The evolution of this Archean terranes has been divided into three main stages. The first related to the generation of a primitive and mostly undifferentiated mafic crust (our initial conditions), the second related to plume-related magmatism and generation of the first TTGs and the last one with the stabilization of the cratonic lithosphere (Van Kranendonk et al., 2015). Our results represent the second stage, in which the hot mantle upwelling starts interacting with the proto lithosphere. During this stage, a primitive continental crust is slowly generated, with a composite mafic volcanic sequence composed of komatiites, high $\mathrm{Mg}$ basalts, and tholeiite (Van Kranendonk et al., 2015). The felsic crust generation is associated with delamination and dripping events, that catalyse the production of an ultra-depleted mantle and felsic crust production. In this stage, the mantle is potentially hydrated and contaminated by the delaminated crust Bédard (2006).

Low $T_{P}$ regimes $\left(\leq 1450^{\circ} \mathrm{C}\right)$ In these experiments, there are plate-boundaries-like features that are associated with the production of middle- to high-pressure felsic melts. Within the same settings coexist different structural patterns and modes of felsic melts production. The lithospheric mantle is rigid and less prone to be captured by the delaminating crust preventing the asthenosphere from partially melting outside the internal zone. The propagation of the internal zone generates annular predominantly felsic terranes that assist the sub-accretion of the initial lithosphere. Itsaq gneiss complex (West Greenland) is an old Archean terranes mainly composed of felsic gneiss that records a potential long phase of horizontal tectonics (Nutman et al., 2013, 2009). The horizontal tectonic phases have been interpreted as a consequence of subduction-related processes (Nutman et al., 2013, 2009). Sizova et al. (2015) using 2D numerical experiments shows that subduction-like processes arise as a consequence of the chemical evolution of the crust, and associated the generation of predominantly felsic crust terranes with transient subduction events. Our results show that vertical tectonic processes generate significant horizontal displacement, generating stacking of felsic crust slivers due to the co-operation of RTIs, delamination and mantle drag. Although, we do not explicitly simulate the felsic crust reworking, these thickened continental terranes would eventually undergo partial melting generating further evolved continental crust. It is widely believed that continental crust forming processes evolve with the secular cooling of the planet (Moyen \& Martin, 2012; Ganne \& Feng, 2017; Palin et al., 2020). Several lines of research suggest that the felsic crust produced become progressively potassic and that the pressure of generation of the felsic melts increased (Laurent et al., 2014). Our low $T_{P}$ regimes show behaviour that is consistent with these observations and importantly show that these contrasting $P-T$ conditions may coexists together.

In our numerical experiments, the interaction between the transient plume and lithosphere generates a semi-circular structure that radially expands with velocities that depends on the background $T_{P}$. In both explored regimes the propagation of the internal zone is accompanied by disintegration of the newly-produced crust, and its lateral displacement over several 100s km. These structural feature resembles the coronae structure on the surface of Venus (Harris \& Bédard, 2014; Stofan et al., 1992). Most of the deformation is governed by three main processes: the drag force exerted by the astenosphere that rises as a consequence of the RTIs and delamination processes; pulls forces exerted by the foundering drips and delamination of the lower crust at the boundary zones.

Our results can be compared with numerical experiments exploring plume-induced subduction (Ueda et al., 2008; Baes et al., 2016; Gerya et al., 2015). The main target parameters of these previous studies has been the plastic and viscous strength of the lithosphere and the buoyancy of the plume. These works discovered four regimes through which a simulation evolves: 1) underplating plume; 2) crustal fragmentation; 3) transient subduction; 4) self-consistent subduction. Our results characterize the first regime, and soon evolve into crustal fragmentation Ueda et al. (2008) due to crustal gravitational instabilities. In the 3D numerical experiments, a strong crustal fragmentation occurs at high $T_{P}$, that prevents the formation of any localized deformation zone. By contrast in the low $T_{P}$ cases, the combination of gravitational instabilities and compositional evolution of the crust allows the emergence of plate-like boundaries features.

We observe subduction-like processes that are related to inefficient melt extraction and which emerge due to asthenospheric return flow caused by gravitational instabilities. This inefficient melt extraction does not reduce the melt-induced compositional buoyancy, causing active upwellings that pushes the newly generated crust towards the old-lithosphere forcing under-thrusting (see Fig. 2). These behaviours have also been observed in 3D models (see Fig. S5), but are only a consequence of inefficient melt extraction. The mantle plume in these experiments triggers the gravitational instabilities, but does not cause subduction to initiate. 
Our results show that several plate-like processes occur in a geodynamic scenario dominated by vertical displacements. As noted by Sizova et al. (2015), the emergence of plate-like processes is most likely due to the compositional evolution of the oceanic crust, which also has direct implications for the rock types diagnostic of subduction - such as blueschists - that may form and be preserved in geological terranes through time (Palin \& White, 2016). The generation of plate-like boundaries in low $T_{P}$ experiments provides clear evidence that the compositional evolution of the crust and the plume-induced dynamics generates lateral and vertical heterogeneities, creating weak zones that may ultimately become plate boundaries. It is arguable that the presence of these distinctive compositional and structural domains can evolve into modern-style subduction zones. If these zones connect and become a global network, the transition from a stagnant lid regime to a mobile lid (plate tectonic) geodynamic regime may proceed.

\section{Conclusion}

Our 2D and 3D numerical experiments predict several fundamental differences in the styles of plume-lid interaction as a function of initial lithosphere thickness and initial $\mathrm{T}_{P}$. At high $\mathrm{T}_{P}$ most of the deformation and production of new mafic crust is mediated by asthenospheric mantle flow resulting from gravitational instabilities $\left(T_{P} \geq 1500^{\circ} \mathrm{C}\right)$. At low $\mathrm{T}_{P}\left(T_{P} \leq 1450^{\circ} \mathrm{C}\right)$ most of the newly generated crust is closely related to plume activity. This variability of temperature at which basalt is generated supports the idea that upper mantle $T_{P}$ may have been lower, and indicate that mafic crust is composed of different mafic lithologies. As a consequence, it is necessary to address the effect of this variability to constraint the condition at which natural Archean TTGs are generated. Our numerical experiments predicts that significant amount of new felsic crust are produced, even though, the $P-T$ conditions do not match the most previously suggested ranges that are thought necessary to produce high amounts of TTGs-like melts, indicating that further investigation is required.

\section{Acknowledgments}

DFG grant, SPP 1833 Building a Habitable Earth has supported this research. B.J.P.K. has been supported by MAGMA Consolidator Grant (ERC project 771143). The data are accessible upon request to the first author. We acknowledge Adina E. Püsok and Tobias S. Baumann for the useful suggestion that improved the visualization of our numerical experiments, Anton A. Popov for the useful suggestions and tip provided during the implementation of melt extraction algorithm, and N. Berlie, N. Riel and E. Moulas for the discussions and insights provided. The manuscript has been significantly improved thanks to comments of J. Bedard, J. Van Hunen and an two anonymous reviewers.

Table 1: Composition of mantle phases diagram. All the compositions are listed as mole \% oxide.

\begin{tabular}{|c|c|c|c|c|c|c|c|}
\hline Rock Type & $\mathrm{SiO} 2$ & $\mathrm{Al} 2 \mathrm{O} 3$ & $\mathrm{Cr} 2 \mathrm{O} 3$ & $\mathrm{FeO}$ & $\mathrm{MgO}$ & $\mathrm{CaO}$ & $\mathrm{Na} 2$ \\
\hline MD0\% & 48.809 & 8.195 & 1.066 & 10.438 & 27.501 & 3.590 & 0.4 \\
\hline MD10\% & 49.235 & 7.047 & 1.126 & 10.241 & 29.232 & 2.843 & 0.27 \\
\hline MD20\% & 49.782 & 5.463 & 1.156 & 10.161 & 31.385 & 1.924 & 0.1 \\
\hline MD30\% & 50.328 & 3.815 & 1.163 & 10.023 & 33.930 & 0.723 & 0.0 \\
\hline MD40\% & 50.202 & 3.327 & 1.070 & 9.517 & 35.782 & 0.102 & $0.0 \mathrm{C}$ \\
\hline MD50\% & 49.309 & 3.608 & 0.994 & 8.812 & 37.276 & 0.001 & 0.00 \\
\hline
\end{tabular}

Table 2: Composition of basalts. All the compositions are listed as mole \% oxide. (*) Basalt Step $45 \%$ has the same phase diagram of Basalt Step $30 \%$, but, after the extraction, the predicted composition is the one listed. Basalt Step $45 \%$ is used to describe the density of the dry Intrusions. 


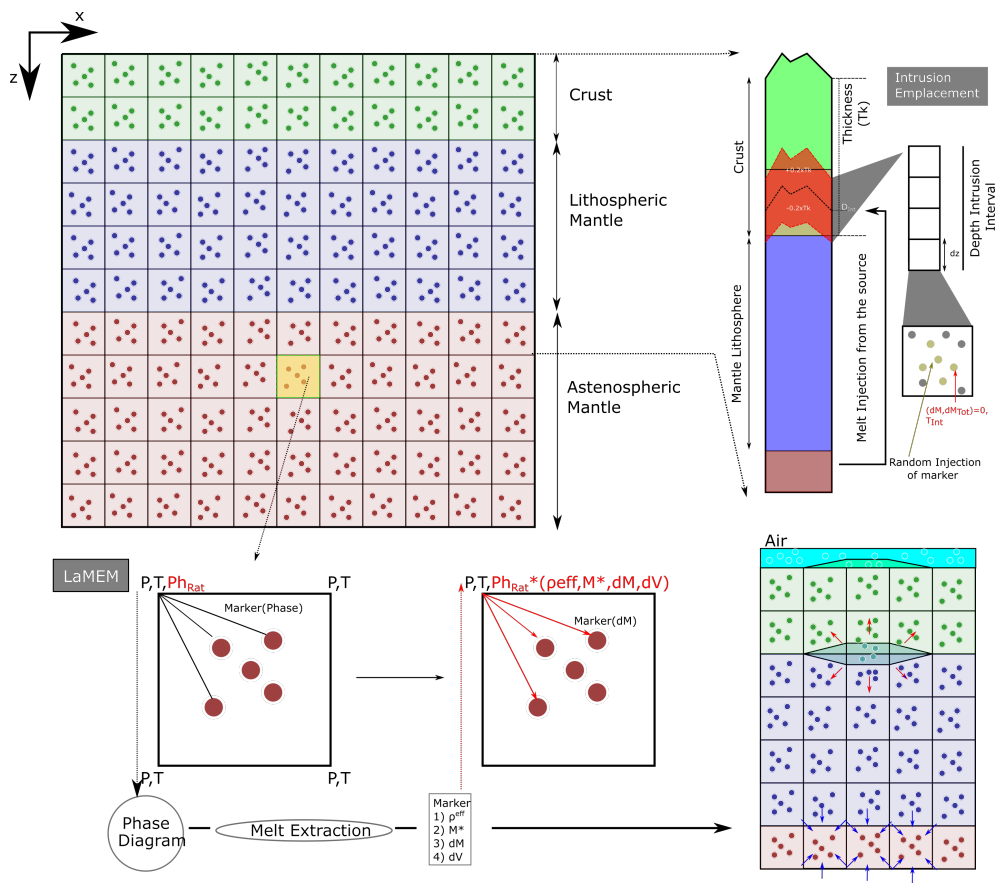

Figure 1: Schematic representation of melt-extraction algorithm. For each timestep all the rock-type properties are interpolated into the main grid. Then from pressure and temperature, the density and melt quantity are interpolated from the phase diagrams and scaled accordingly to the $P h_{\text {Rat }}$. After the computation of the total melt extracted, the negative and positive source term are applied to the grid. The intrusion emplacement depth interval is chosen according to the relative depth to the Moho, and the injected volume is evenly distributed along this depth interval 
A PREPRINT - FridAy $21^{\text {ST }}$ MAY, 2021

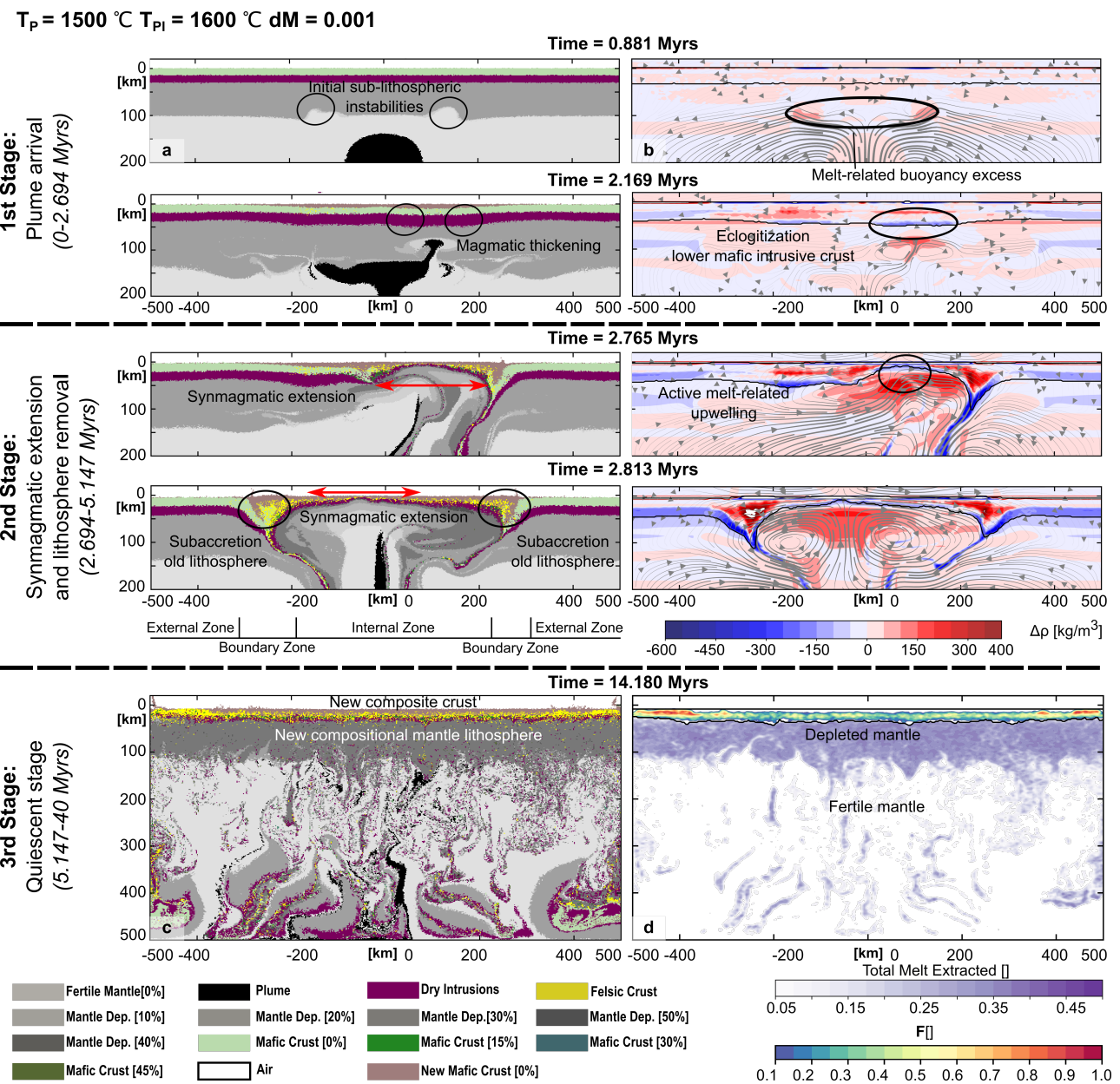

Figure 2: Main evolutionary stages of the low $\mathrm{dM}$ numerical experiment. The sub-plots of the 1st and 2nd stage zoom in on the lithospheric scale processes $(-20-200 \mathrm{~km})$. Column a) features sub-plots represents the compositional field, while column b) shows several snapshots of the buoyancy contrast that controls the evolution of the numerical experiment, the black thick lines represent the internal free surface and the Moho topography, while the grey arrows represent the streamline of the velocity field. $\Delta \rho$ is computed by subtracting the density field along $\mathrm{x}$ direction for a given depth from the average density of the considered depth $\left(\Delta \rho(x, \mathbf{z})=\rho(x, \mathbf{z})-\rho_{\text {mean }}(\mathbf{z})\right.$, where $\mathbf{x}$ represents the $\mathbf{x}$ coordinate, and $\mathrm{z}$ represents the given depth). Therefore, this parameter represents the excess (negative values) and the deficiency (positive) of mass with respect to the background density. The snapshots of the 3rd stage represents the full numerical domain during the quiescent stage. c) represents the full compositional domain, while d) represents both the volumetric fraction of melt extracted from the mantle during the whole simulation, and the volumetric fraction of felsic crust components within the crust. The black thick lines represent the free surface and the Moho depth. 


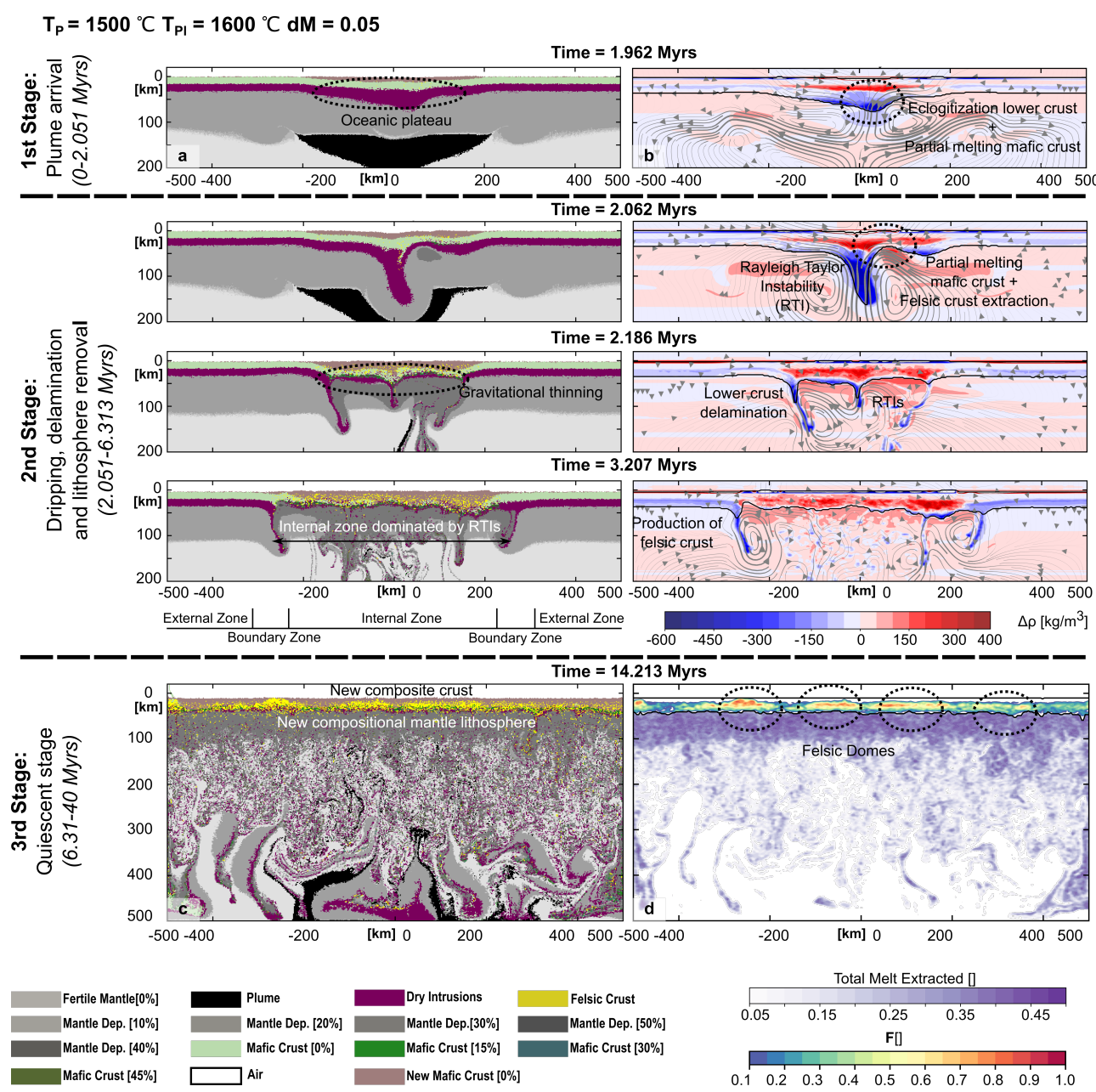

Figure 3: Main evolutionary stages of the high $\mathrm{dM}$ numerical experiment. The sub-plots of the 1st and 2nd stage zoom in on the lithospheric scale processes (-20 -200 km). Column a) features sub-plots represents the compositional field, while the column b) shows several snapshots of the buoyancy contrast (see the caption of Fig.2 for further explanations), with the streamline of the velocity field, the black thick lines represent the internal free surface and the Moho topography. The snapshots of the 3rd stage represents the full numerical domain during the quiescent stage. c) represents the full compositional domain, while d) is a plot that represents both the volumetric fraction of melt extracted from the mantle during the whole simulation, and the volumetric fraction of felsic crust (F) components within the crust. The black thick lines represent the internal free surface and the Moho topography. 

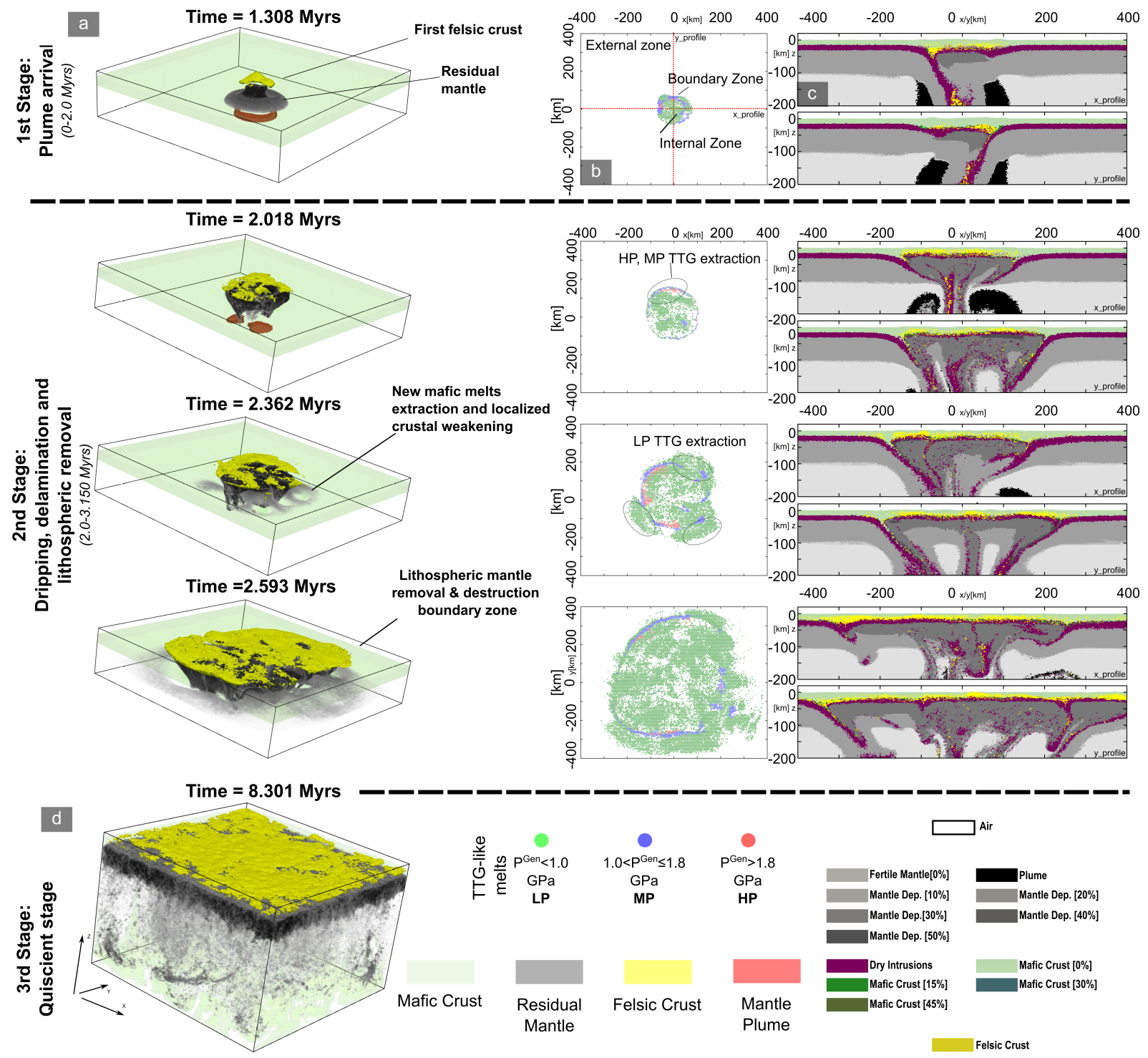

Figure 4: Temporal evolution of the high potential temperature reference scenario $\left(\mathrm{T}_{P}=1500{ }^{\circ} \mathrm{C}, \mathrm{R}=200 \mathrm{~km}, \mathrm{~T}^{P l}=1600{ }^{\circ} \mathrm{C}, \mathrm{dM}=\right.$ $0.05, \mathrm{M}^{\text {trs }}=0.001, \mathrm{I}_{R}=0.6$ ). The $1 \mathrm{st}$ and $2 \mathrm{nd}$ stage zoom in on the first $200 \mathrm{~km}$ of the numerical domain. The column a) represents a simplified compositional field (mafic crust collects all the mafic protolith phases, the residual mantle comprises all the mantle residual phases generated during the ongoing simulation, felsic crust represents the new granitoids emplaced, and red colour represent the initial plume). b) 2D maps that represent the distribution of LP (green dots), MP (blue dots) and HP (red dots) TTG like melts extracted; c) This represent slices of the compositional field taken along $\mathrm{x}$ and y direction; d) Represents simplified compositional field of the whole numerical domain. 

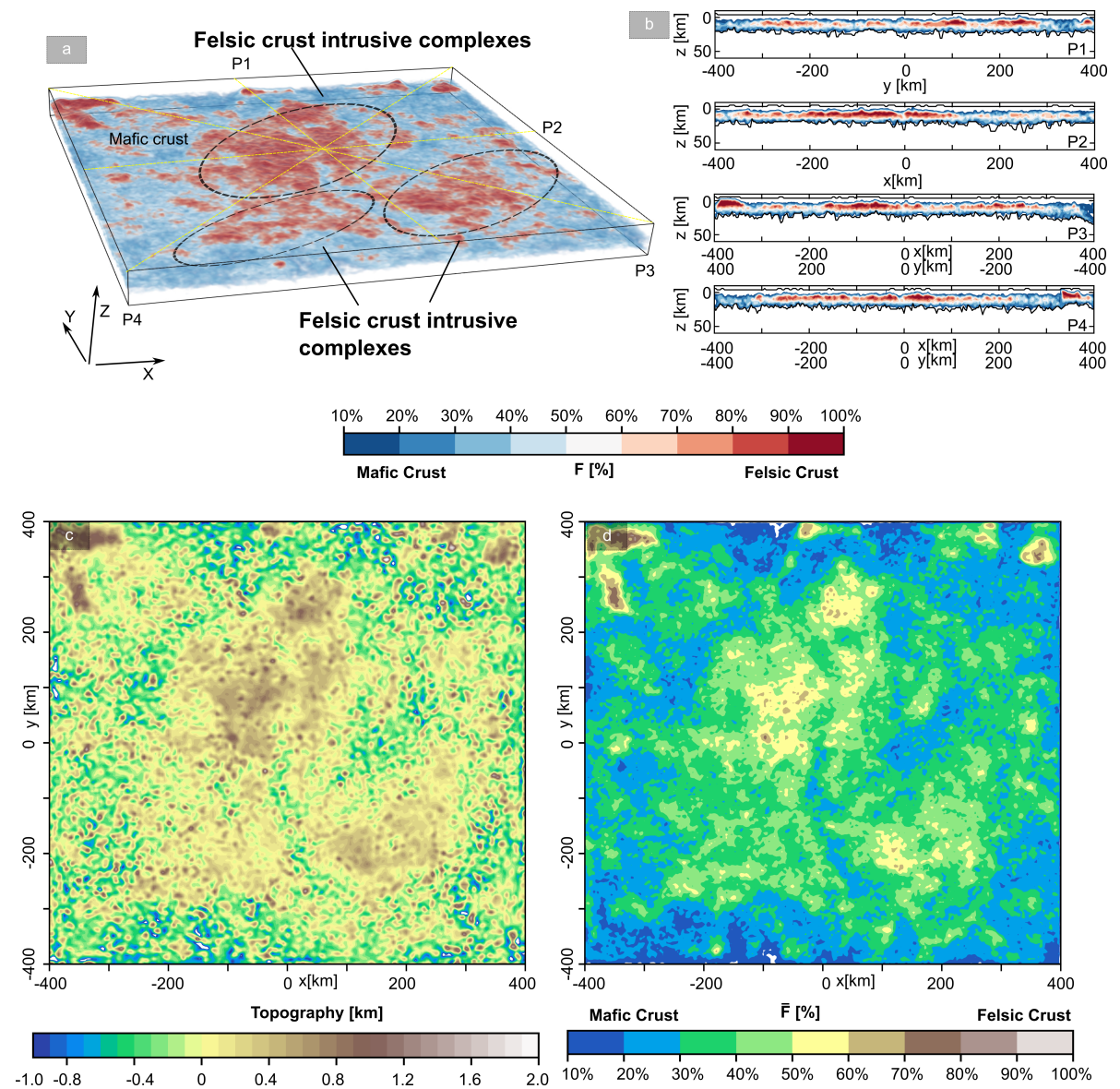

Figure 5: Final composition of the crust, and the effect of crustal material on the topography (the topography is computed using as a reference the average depth of the internal free surface). a) The plot represents the fractional volume of felsic components (F) within the crust; the yellow lines represent the direction of the profiles that are shown in b). b) Slices of the figure a). The volumetric fraction of felsic components is not homogeneously distributed within the volume of the crust. The highest values of $\mathbf{F}$ are associated with felsic domes, with irregular shapes. The black thick lines represent the free surface and the Moho depth. c) 2D contour of topography. The highest elevations are associated with the felsic domes seen in a), while the basins are associated with a relatively mafic component enriched crust; d) 2D map representing the crustal felsic crust composition $(\bar{F})$. $\bar{F}$ represents the volumetric fraction of felsic components within a column of material. 
A PREPRINT - FRIDAY 21 ${ }^{\text {ST }}$ MAY, 2021
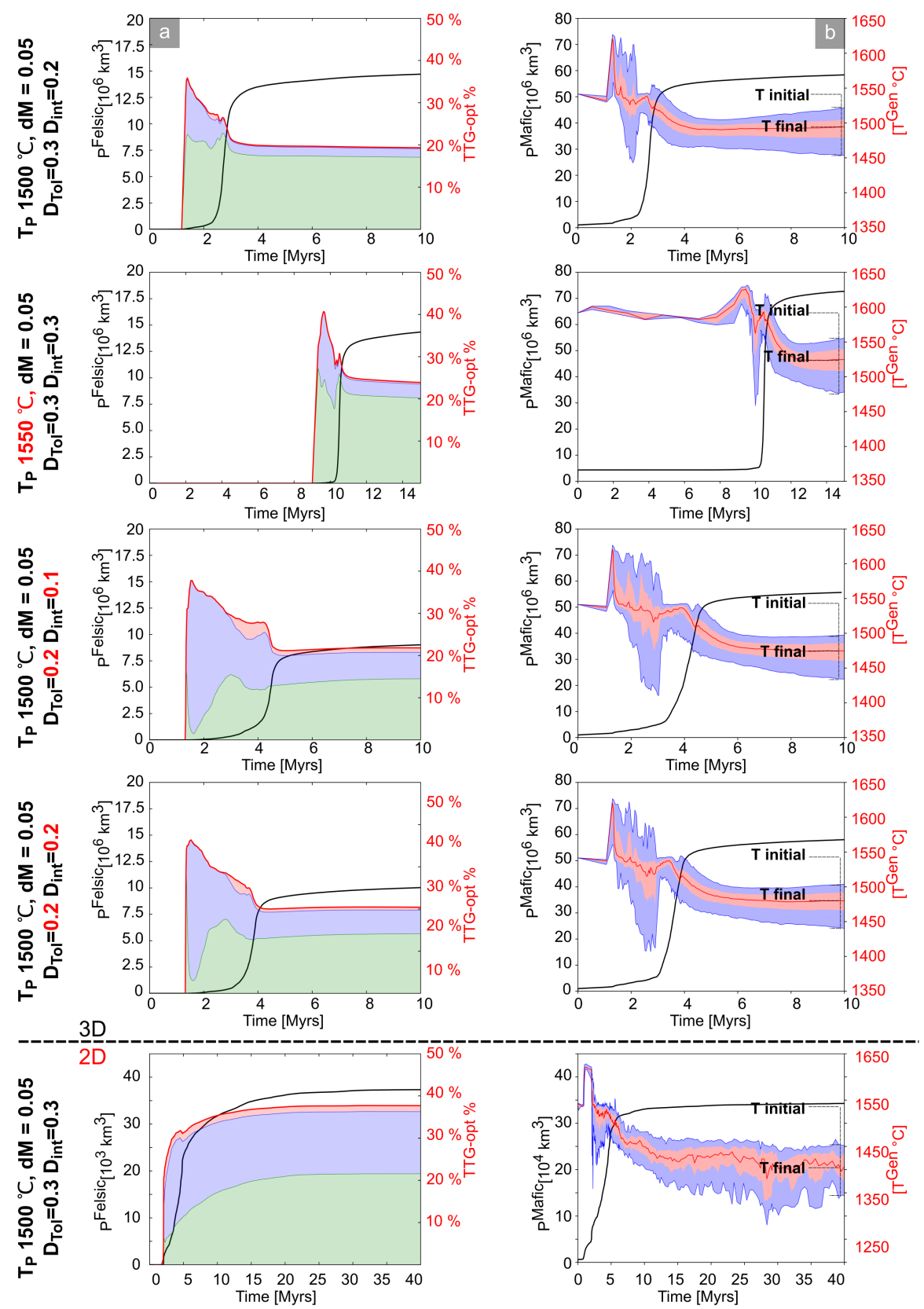

Figure 6: Summary of the felsic and mafic melt extraction P-T conditions of the high $T_{P}$ regimes experiments. Each row represents different experiments. The parameters that have been changed respect the high $T_{P}$ reference scenarios shown in Fig. 4 are highlighted in red. The last row is the $2 \mathrm{D}$ numerical experiments, which feature the same input parameter of the high $T_{P}$ reference scenarios. The evolution of this experiment is shown in Fig. 3 .a) Felsic melt extraction conditions: left axis and black thick line represents the cumulative volume of felsic melts produced during the simulation (i.e. the felsic crustal growth curve); the right axis and the red thick line represents the cumulative volumetric fraction of TTG-like melts produced during the simulation. The shaded green, blue and red area represents LP-TTG, MP-TTG and HP-TTG like melts cumulative volumetric fraction respectively. b) Mafic melts extraction conditions: left axis and black thick line represents the cumulative volume of mafic melts extracted (i.e. the mafic crustal growth curve) during the simulation; right axis and red thick line represent the temperature of extraction of mafic melts $\left(T^{G e n}\right)$.The blue shaded area represents the temperature conditions in which 5-25\% and 75-95\% of melts are extracted. While the red shaded area represents the standard deviation of the $T^{\text {Gen }}$ during the simulation evolution. The initial temperature and final temperature are highlighted in the right of each plot to highlight the effective cooling of the mantle during the whole simulation. 

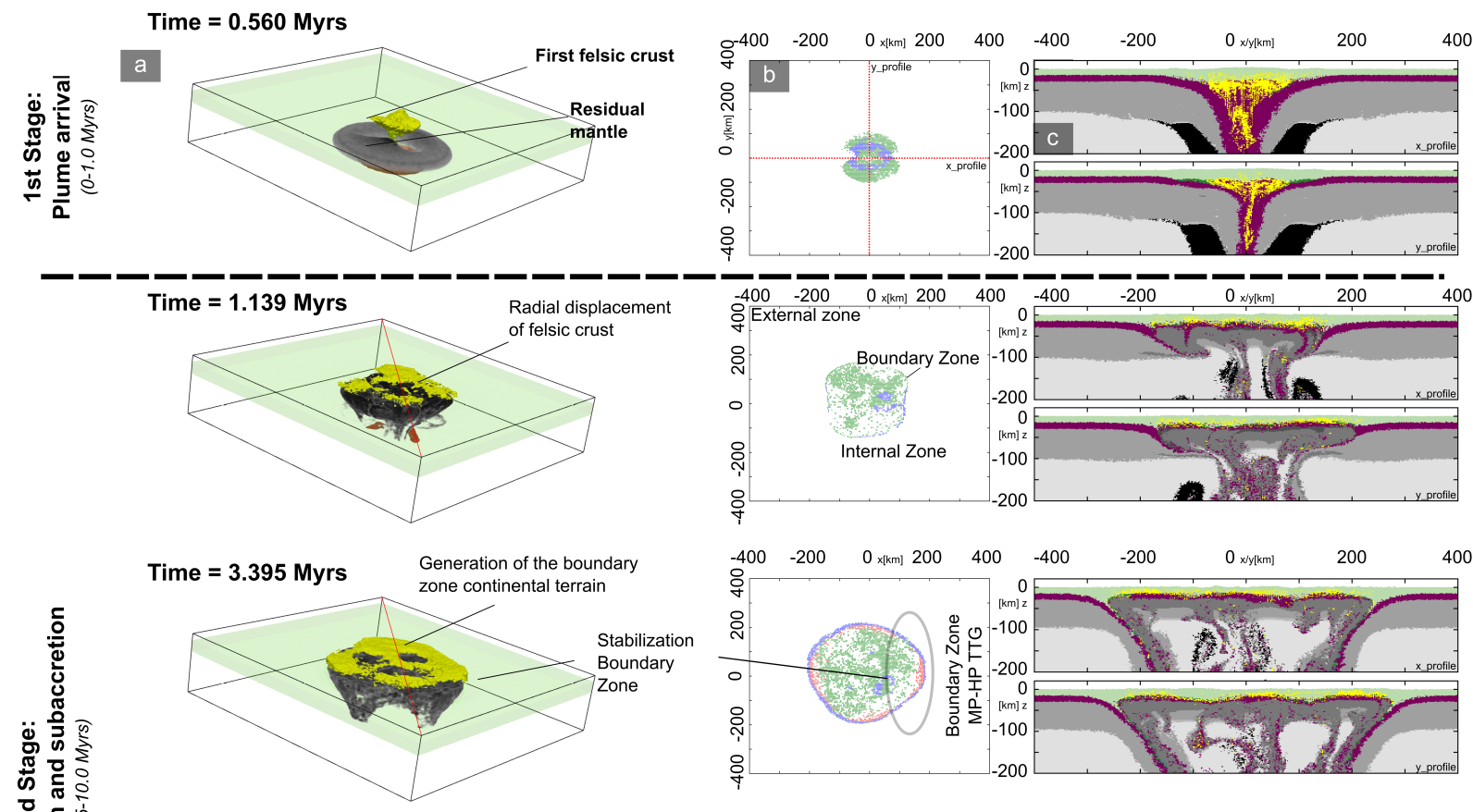

을
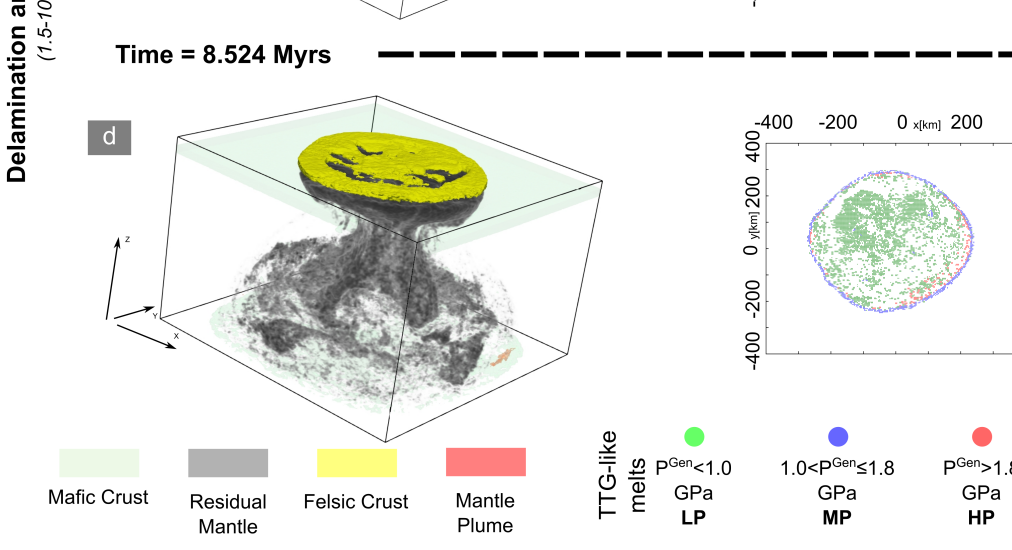

$-200$
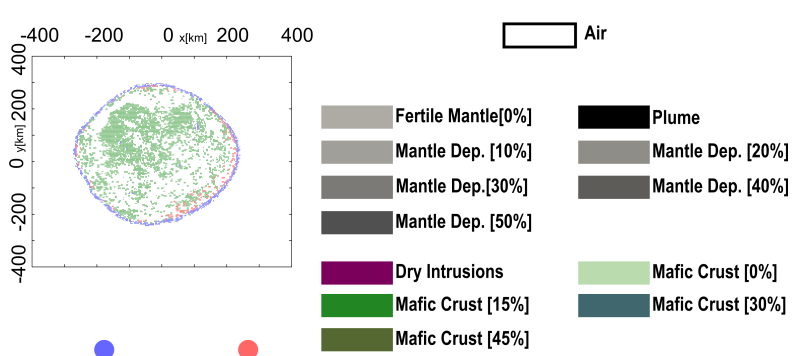

Figure 7: Temporal evolution of the low $T_{P}$ reference scenario $\left(\mathrm{T}_{P}=1400{ }^{\circ} \mathrm{C}, \mathrm{R}=200 \mathrm{~km}, \mathrm{~T}^{P l}=1600{ }^{\circ} \mathrm{C}, \mathrm{dM}=0.05, \mathrm{M}^{\text {trs }}=0.001, \mathrm{I}_{R}\right.$ $=0.6$ ). The column a) represents a simplified compositional field (mafic crust collects all the mafic protolith phases, the residual mantle comprises all the mantle residual phases generated during the ongoing simulation, felsic crust represents the new granitoids emplaced, and red colour represent the initial plume). All the figures represents the compositional field evolution in the first 200 $\mathrm{km}$ of the numerical domain, except for the figure in the bottom row that represents the whole numerical domain. The column $\mathrm{b}$ ) are a set of 2D map that represent the distribution of LP (green dots), MP (blue dots) and HP (red dots) TTG like melts extracted; c) This represent slices of the compositional field taken along $\mathrm{x}$ and y direction; $\mathrm{d}$ ) Represents simplified compositional field of the whole numerical domain. 


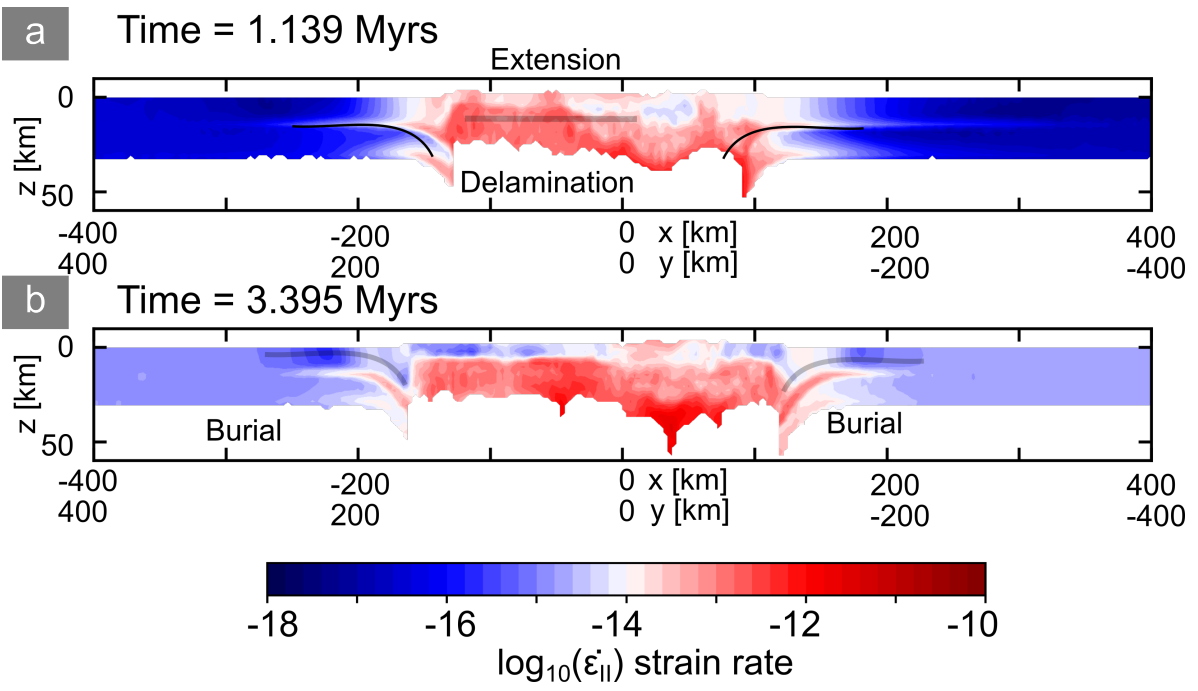

Figure 8: Two crustal scale slices of the second invariant of the strain rate. The profiles are taken along the two thick red lines shown in the compositional plot at 1.139 and 3.395 Myrs in Fig. 7. These profiles focus on the evolution of the boundary zone, that thickens with time. The thickening is associated with the over thrusting of the annular continental terrain into the external zone mafic crust. The over thrusting processes are associated with a burial of the mafic crust and allows the production of MP and HP TTG like melts. 

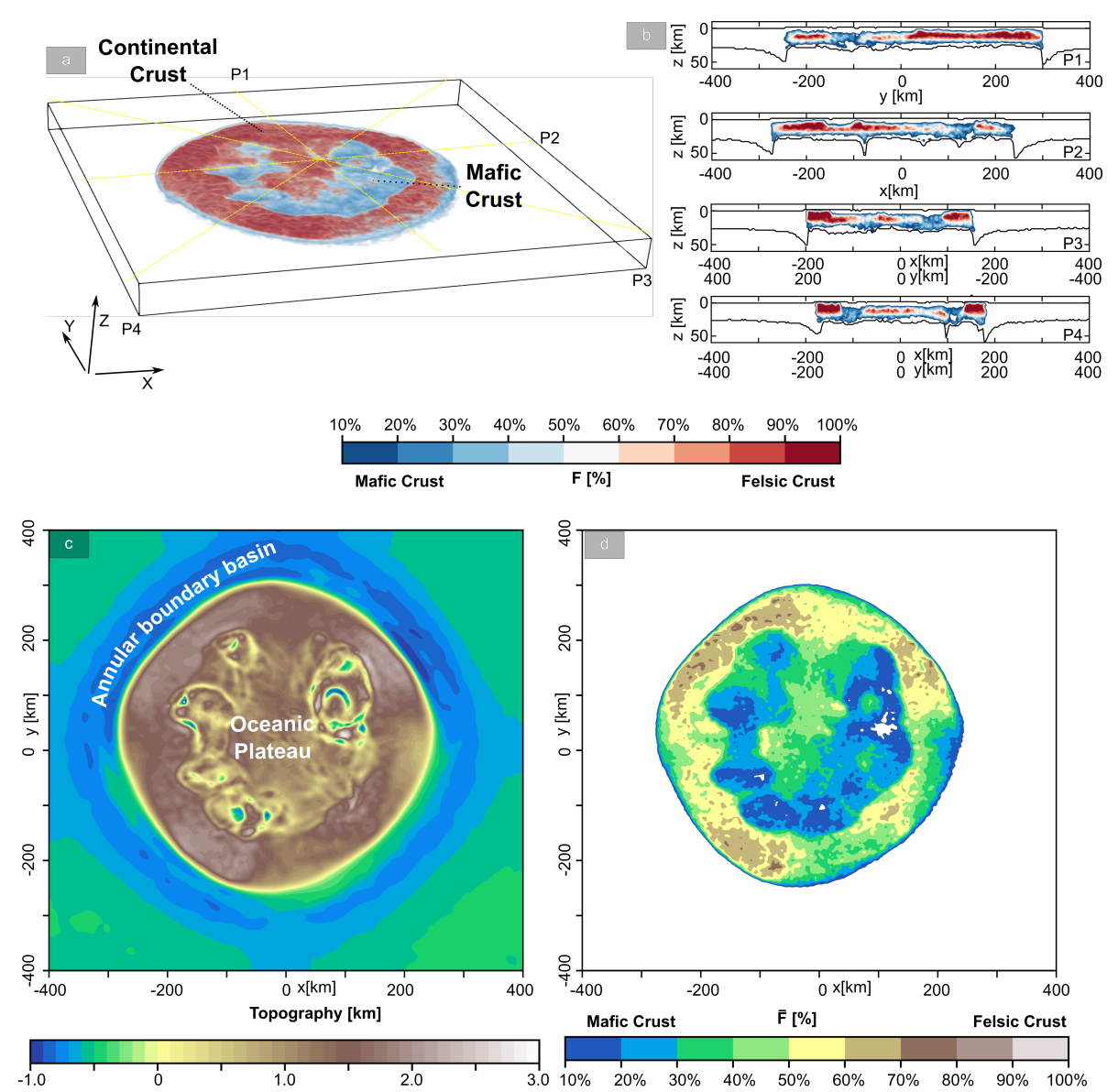

Figure 9: Final composition of the crust, and the effect of crustal material on the topography (the topography is computed using as a reference the average depth of the internal free surface) of the low potential temperature reference scenario. a) Represents the volume fraction of felsic crustal component within the crust. The thick yellow line represents the direction of the slices that are shown in b). b) Slice of volumetric fraction of felsic crust material. c) Topography of the experiments at the end of the explored timescale. The elevation distribution is correlated with the anomalous volume of felsic material. The strongest topographic gradient is observed in the boundary zone due to the over thrusting of the annular continental terranes into the external zone mafic crust. d) Felsic crustal composition map $\bar{F}$. 
A PREPRINT - FrIDAY $21^{\text {ST }}$ MAY, 2021
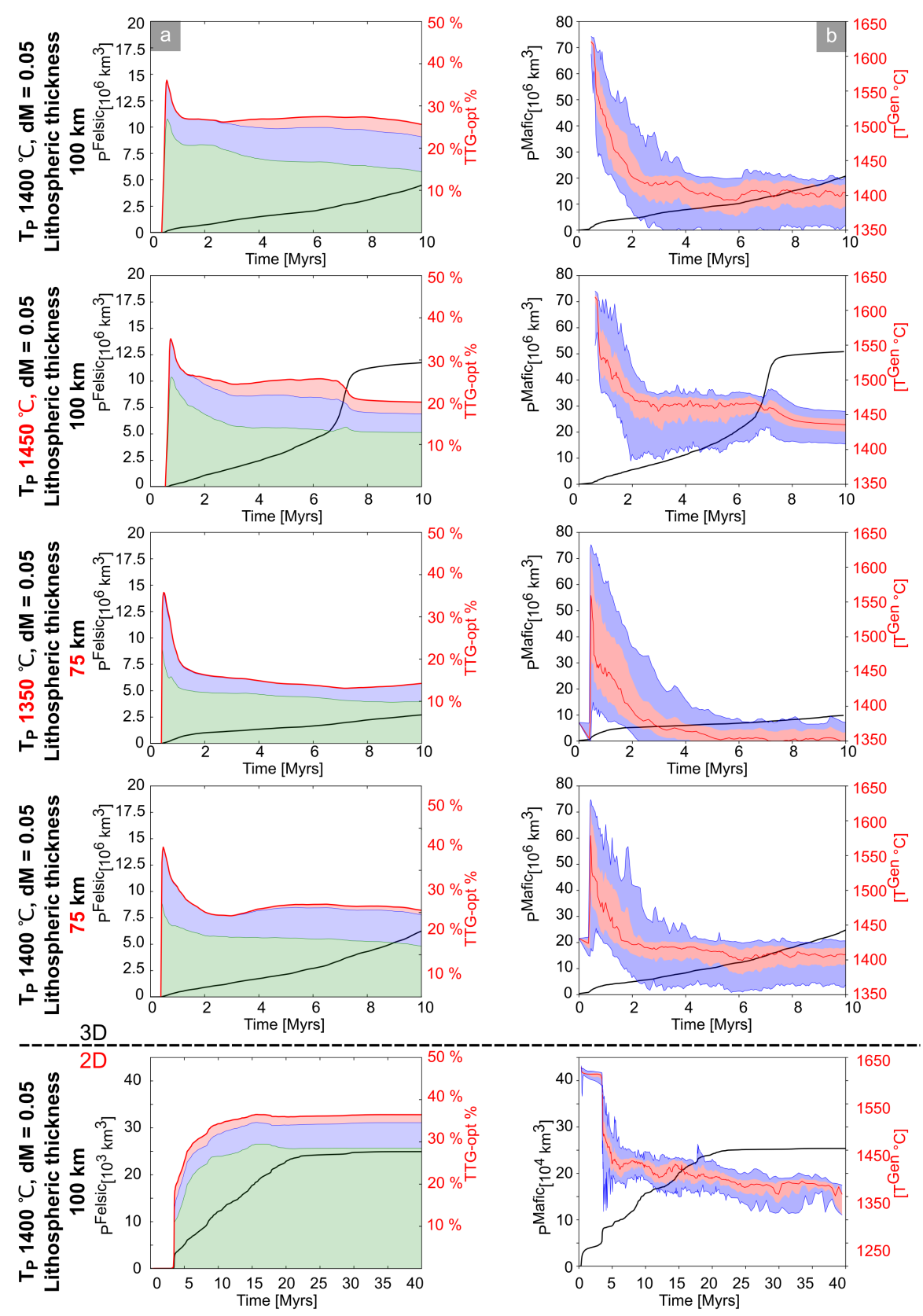

Figure 10: Summary of the felsic and mafic melt extraction P-T conditions of the low $T_{P}$ regimes experiments. Each row represents different experiments. The parameters that have been changed respect the low $T_{P}$ reference scenarios shown in Fig. 8 are highlighted in red. The last row is the $2 \mathrm{D}$ numerical experiments, which feature the same input parameter of the low $T_{P}$ reference scenarios .a) Felsic melt extraction conditions: left axis and black thick line represents the cumulative volume of felsic melts produced during the simulation (i.e. the felsic crustal growth curve); the right axis and the red thick line represents the cumulative volumetric fraction of TTG-like melts produced during the simulation. The shaded green, blue and red area represents LP-TTG, MP-TTG and HP-TTG like melts cumulative volumetric fraction respectively (the proportion of each category at the end of the numerical experiments are listed in Tab. S3). b) Mafic melts extraction conditions: left axis and black thick line represents the cumulative volume of mafic melts extracted (i.e. the mafic crustal growth curve) during the simulation; right axis and red thick line represent the temperature of extraction of mafic melts $\left(T^{G e n}\right)$. The blue shaded area represents the temperature conditions in which $5-25 \%$ and $75-95 \%$ of melts are extracted. While the red shaded area represents the standard deviation of the $T^{\text {Gen }}$ during the simulation evolution. 

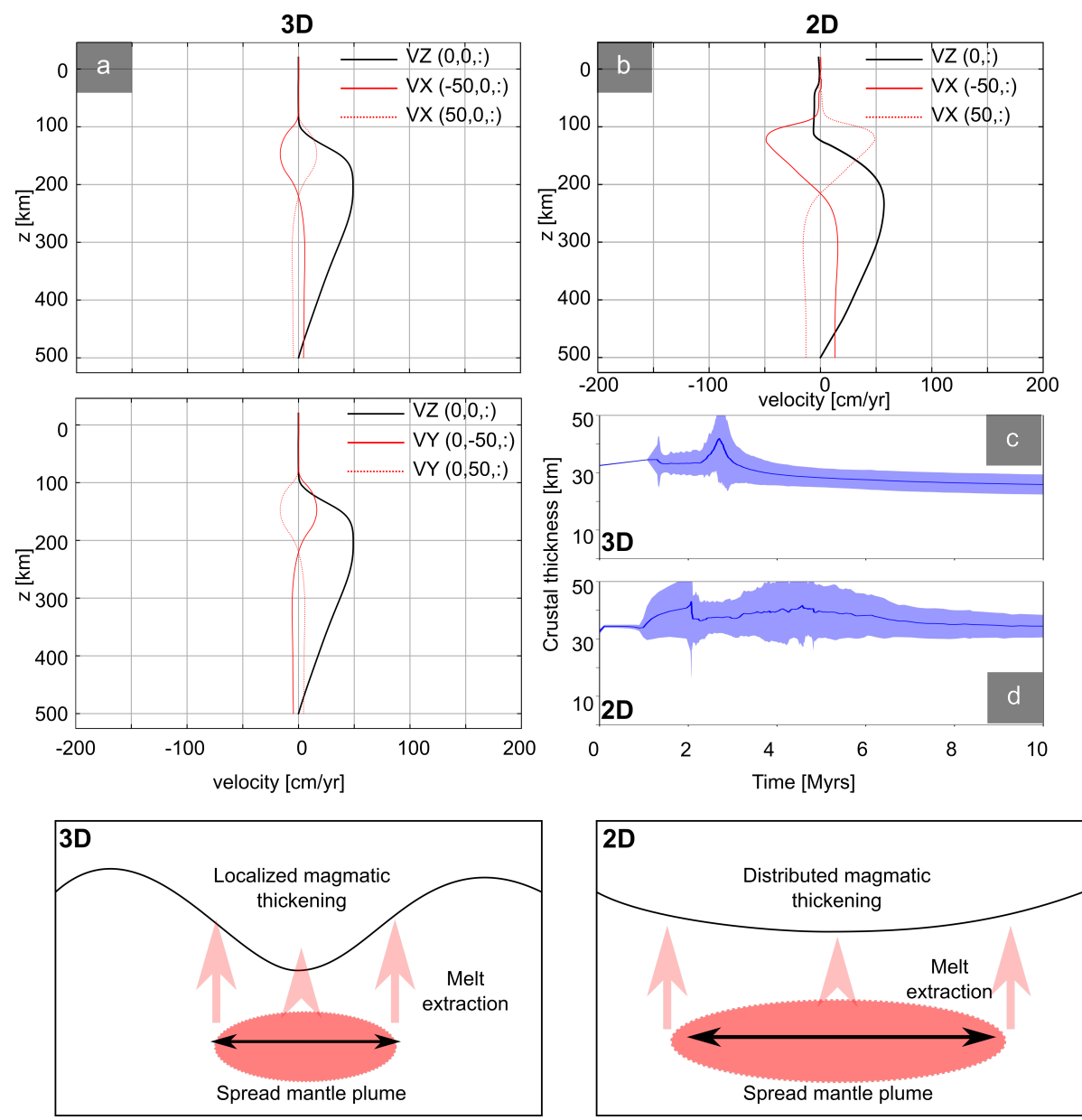

Figure 11: Velocities profiles of both 2D and 3D numerical test shortly before the removal stage, and the evolution of the crustal thickness. At the bottom of the figure, two simple sketches highlight the main difference of 2D and 3D numerical experiments. a) These two pictures represent the velocity field observed in the 3D numerical simulation shown in Fig.4. The black thick lines represent the $\mathrm{z}$ component of the velocity along the plume axis, while the red lines represent the $\mathrm{x}$ or $\mathrm{y}$ velocity component took at $\pm 50 \mathrm{~km}$ along $\mathrm{x}$ or $\mathrm{y}$ direction from the plume axis. b) This picture represents the velocity field observed in the $2 \mathrm{D}$ numerical experiments shown in Fig.3. The black line represents the $\mathrm{z}$ component of the velocity along the plume axis, while the red line the $\mathrm{x}$ components of the velocity field taken at $\pm 50 \mathrm{~km}$ along the $\mathrm{x}$ direction from the plume axis. c) Average crustal thickness evolution with time of the 3D numerical experiments; d) Average crustal thickness evolution of the 2D numerical experiment. 
A PREPRINT - FridAY $21^{\text {ST }}$ MAY, 2021

\section{Supplementary Material}

\section{Post-processing and hardware information}

LaMEM is a finite-difference staggered-grid code. Melt extraction is performed in the central nodes, which are the one used to compute the continuity equation and where temperature and pressure are defined. The output grid used for visualization and data analysis is defined on the corner nodes of the staggered-grid, and all the variables are interpolated on the visualization grid. This interpolation might affect melt extraction temperatures, as the interpolation slightly smoothen the temperature variation. Furthermore, most of the data are picked each time the output is created. This strategy was necessary to minimize the amount of memory needed to store the numerical experiments. As a consequence, the melt extraction events that we used in our analysis are affected by both interpolation scheme and the number of output steps that are produced. The data concerning TTGs melting condition represents a small population of the total conditions of extractions. 2D experiments are less memory demanding than $3 \mathrm{D}$, and we saved the output every 50 timesteps, while 3D experiments outputs were saved every 200 timesteps. 2D numerical experiments required 10-20 thousand timesteps to be completed ( 40 Myrs model time, $2-3$ weeks per run), while 3D experiments required 30-40 thousands timesteps ( 10 Myrs model time, 2-3 months per simulations on 512 cores).

\subsection{Moho identification and internal free surfaces}

We divided the rock-types into three main categories: 1) Mantle (Ml); 2) Mafic crust $(M C)$; 3) Continental crust (CC). At each timestep, the phase proportion of the three categories are computed by summing the phase ratio of mantle, mafic and continental rock-types respectively. To constraint the Moho depth LaMEM sums the contribution of $C C$ and $M C$, after which it loops from bottom to top saving the $z$ coordinates of the nodes featuring $C C+M C<0.8$ (during this operation the air phases is considered part of the crust as well).

The internal free surface is defined at the beginning of the simulation. The resolution of this surface is the horizontal resolution of the numerical experiments (e.g. $3.125 \mathrm{~km}$ in the simulation described in the current work). After the system of equations is solved, the velocity field is linearly interpolated from the main grid to the actual position of the internal free surface (see Fig.S1 1)). Then the free surface is advected in accordance of all the velocity component (in the simplified sketch of Fig.S1, we show only the advection as a function of the $z$ component of the velocity). Then the new advected topography is interpolated back to the main horizontal grid. After the advection of the free surface, the particles above and below the free surface are eventually corrected, and their phase is changed to be air or rock phase as a function of their relative position to the new free surface position. After all these corrections, that are necessary to prevent that rocks phase are above the actual free surface, the volume of effusion is converted into an effusive thickness. The computation of the total volume of melt extracted is the cumulative summation of all the volumetric contribution along a column whose area is equal to the finite difference cell area (e.g. $9.765 \mathrm{~m}^{2}$ ). To compute the effective thickness of new crust added at the top of the free surface, this volume of extracted material is conceived to be equivalent to the volume of a rectangular prism whose base is represented by the finite difference cell area and its height is the unknown effective thickness of new crust. The effusive thickness $\left(\delta_{\text {eff }}[\mathrm{m}]\right)$ is computed (see S13)):

$$
\delta_{e f f}(x, y)=\frac{V_{o l} l_{e f f}}{d x \cdot d y}
$$

However, the effective thickness is defined in the cell center of the main numerical grid. Therefore this values must be linearly interpolated into the main grid. After the interpolation, the free surface is shifted accordingly to the local $\delta_{e f f}$ and the area between the previously computed free surface and the new one is filled with effusive rocks (see S14). The cumulative melt production is computed by summing the total melt extracted along $z$ direction, at every timestep:

$$
V_{c u m}^{\text {Tot }}(i, j, M l / M C, t)=\sum_{d t s=1}^{t s} V_{\text {ext }}^{T o t}(i, j, M l / M C)(i)
$$

$i, j$ are the grid indexes, $V_{c u m}^{\text {tot }}$ is the total volume cumulated during the whole simulation and computed for $M C$ or $M l$, $t s$ is the current time-step $(t s)$, while $d t s$ is the time-step increment. Generation temperatures $\left(T^{G e n}\right)$ are computed each time-step, averaging the temperature at which the mafic melts are produced along $z$ direction and considering the volumetric contribution of each rock-type.

$F$, the relative amount of felsic crust, is computed by integrating all the $C C$ phase ratio along $z$ direction divided by the local thickness $(T k)$ of the crust. The integration is within the local Moho depth and the topography (Topo): 


\subsection{Hardware information and solver option}

The simulations were perfomed using the supercomputers offered by Johannes Gutenberg University, MOGON and MOGONII (hpc.uni-mainz.de). LaMEM is a PETSc based code (Balay et al., 2018), and the solving of the non linear system of equation were performed thanks to the PETSc infrastructure. 2D experiments were performed using 8 cores and using the direct solver mumps, the internal linear solver is fgmres with a maximum of 30 linear iteration, and relative tolerance of $10^{-6}$; while the external non linear solver were allowed to iterate maximum 30 times, and the relative tolerance was set to be $10^{-6}$. 3D numerical experiments were performed using 512 processors and using Eisenstadt-Walker methods, with a tolerance spanning from $10^{-1}$ to $10^{-4}$; the internal linear solver fgmres and the number of iteration allowed spans from 4 to 180.

\section{Supplementary table and figures}

\subsection{Supplementary Tables}

Table S1: List of symbols and relative unit of measure

\begin{tabular}{|c|c|c|}
\hline Symbol & S.I. unit & Definition \\
\hline$v_{i}$ & $m s^{-1}$ & velocity vector component \\
\hline s & $s^{-1}$ & Negative and positive volumetric source terms \\
\hline$\tau_{i j}, \tau_{I I}, P$ & $\mathrm{~Pa}$ & Deviatoric stress component, 2nd invariant of the deviatoric stress tensor,Pressure \\
\hline$\rho$ & $\mathrm{kgm}^{-3}$ & Density \\
\hline$g$ & $m s^{-2}$ & Gravity acceleration \\
\hline$\dot{\epsilon}_{i j}, \dot{\epsilon}_{i j}^{e l, p l, v i s}, \dot{\epsilon}_{I I}$ & $s^{-1}$ & Strain rate component, elastic,visco,plastic strain rate component,2nd invariant strain rate tensor \\
\hline$\stackrel{\leftrightarrow}{\tau}$ & $\mathrm{Pas}^{-1}$ & Objective deviatoric stress component time derivative \\
\hline$\omega_{i j}$ & $s^{-1}$ & Spin tensor component \\
\hline$G$ & $G P a$ & Shear modulus \\
\hline$\eta$ & Pas & Viscosity \\
\hline$B$ & $M P a^{n} s^{-1}$ & Pre-exponential factor \\
\hline $\mathrm{n}$ & n.d. & Stress exponent \\
\hline$E_{a}$ & $\mathrm{kJmol}^{-1}$ & Activation energy \\
\hline$V_{a}$ & $J M P a^{-1} \mathrm{~mol}^{-1}$ & Activation volume \\
\hline$\phi, \phi_{0}, \phi_{1}$ & $/ /$ & friction angle, initial friction angle, final friction angle \\
\hline$C, C_{0}, C_{1}$ & $\mathrm{MPa}$ & cohesion, initial cohesion, final cohesion \\
\hline$T$ & $K,{ }^{\circ} \mathrm{C}$ & Temperature \\
\hline$k$ & $W K^{-1}$ & Heat conductivity \\
\hline A & $\mu W \mathrm{~kg}^{-1}$ & Radiogenic heating per unit of mass \\
\hline$H_{a}, H_{s}, H_{r}$ & $W m^{-3}$ & Adiabatic, Shear and Radiogenic heating per unit of volume \\
\hline$P h_{\text {Rat }}$ & n.d. & Phase proportion \\
\hline$M_{\text {ext }}$ & n.d. & Melt fraction extracted \\
\hline$V_{\text {ext }}$ & $m^{3}$ & Extracted volume \\
\hline$V_{e x t}^{\text {tot }}$ & $m^{3}$ & Total volume extracted along $z$ \\
\hline$V_{\text {eff }}, V_{\text {int }}$ & $m^{3}$ & Effusion and intrusion volume \\
\hline Vol $l_{\text {cor }}$ & n.d. & Volumetric correction \\
\hline$v_{\text {int }}$ & $m^{3} m^{-1}$ & Volume of intrusion per unit of length \\
\hline$D_{\min }, D_{\max }$ & $m$ & Extreme of depth interval of intrusion \\
\hline$D, D_{\text {int }}$ & n.d. & Relative distance from Moho, and relative half interval of intrusion \\
\hline$\delta_{\text {crust }}, \delta_{T k l}$ & $\mathrm{~km}$ & Crust and lithosphere thickness \\
\hline $\begin{array}{c}\bar{F}, \mathbf{F} \\
\text { MaficlFelsic }\end{array}$ & n.d. & Average amount of felsic crust components along $z$ direction and proportion of felsic crust components at $x, y, z$ coordinates. \\
\hline$P^{\text {Mafic/Felsic }}$ & {$\left[\mathrm{km}^{3}\right]$} & Total amount of mafic or felsic crust produced. \\
\hline
\end{tabular}

Table S2: List of the petrophysical properties and phase diagrams. The symbol and relative unit of measures are listed Tab. S1. All rock types share the same: shear modulus, $(G=40 \mathrm{GPa})$; initial and final friction angle $\left(\phi_{0}=30^{\circ}\right.$ and $\left.\phi_{1}=9^{\circ}\right)$; initial and final cohesion $\left(C_{0}=10 \mathrm{MPa}\right.$ and $\left.C_{1}=3 \mathrm{MPa}\right)$; heat capacity $\left(C_{p}=1200 \mathrm{~J} / \mathrm{K} / \mathrm{Kg}\right)$; thermal conductivity $(k=3)$. (a)Hirth \& Kohlstedt (2004); (b) (Ranalli, 1995). Mantle phase diagrams are produced for the current work, while the mafic crust phase diagrams are taken from Piccolo et al. (2019). 
A PREPRINT - FRIDAY 21 ${ }^{\text {ST }}$ MAY, 2021

Table S3: Test names and list of parameters. $D, D_{\text {int }}, d M$ and $M^{\text {trs }}$ are the melt extraction parameter of mantle phases. The mafic crust extraction parameter are equal for most of experiments $\left(d M=0.01, M^{\text {trs }}=0.08, D=0.7\right.$ and $\left.D_{\text {int }}=0.2\right)$.(1) $A$ of all mantle phases is $0.33 \times 10^{-5} \mu \mathrm{W} / \mathrm{kg}$ and the lower thermal boundary condition is $1600^{\circ} \mathrm{C}$. (2) Mafic crust melt extraction parameters $d M$ and $M^{\text {trs }}$ are 0.08 and 0.15 respectively. $\overline{T T G-o p t}$ is the total proportion of TTG-like melts. $\overline{L P-T T G}, \overline{M P-T T G}$ and $\overline{H P-T T G}$ are the normalized total volume of low, middle and high pressure TTG-like melts. $\overline{L P}, \overline{M P}$ and $\overline{H P}$ are the volumetric weighted proportion of felsic melts produced within low pressure conditions $(\leq 1.0 \mathrm{GPa})$, middle pressure condition $(1.0 \geq \mathrm{P} \leq 1.8$ $\mathrm{GPa}$ ) and high pressure (geq $1.8 \mathrm{GPa}$ ). $\overline{L T}, \overline{M T}$ and $\overline{H T}$ represents the volumetric weighted proportion of felsic melts produced at low temperature condition $\left(\leq 800^{\circ} \mathrm{C}\right)$, middle temperature condition $\left(800-1000^{\circ}\right) \mathrm{C}$ and high temperature condition $(\geq 1000$ $\left.{ }^{\circ} \mathrm{C}\right)$ respectively. $P^{\mathrm{Felsic}}$ and $P^{\mathrm{Mafic}}$ are the cumulative amount of felsic and mafic melts produced within the experiments. The resolution tests lists only the final proportion of the TTG, and the final cumulative volume of both mafic and felsic melts and the final average crustal thickness $\left(\delta_{\text {crust }}^{f a v}\right)$. The input parameters are the same of the Test $3 \mathbf{L}$, except for the number of nodes employed, that results into a different $d x$ and $d z$ and finite difference cell area (A) 
Table S4: The resolution tests lists only the final proportion of the TTG, and the final cumulative volume of both mafic and felsic melts and the final average crustal thickness $\left(\delta_{\text {crust }}^{f a v}\right)$. The input parameters are the same of the Test $3 \mathbf{L}$, except for the number of nodes employed, that results into a different $d x$ and $d z$ and finite difference cell area (A) 


\subsection{Supplementary Figures}

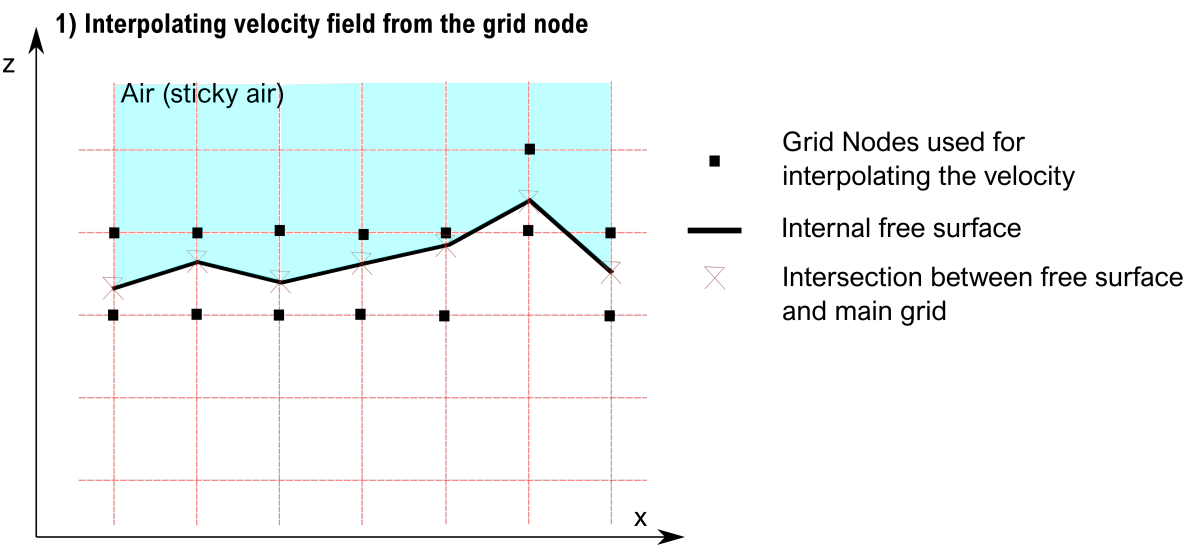

2) Computing the new position of the free surface

3) Computing the new effusive thickness in each nodal point

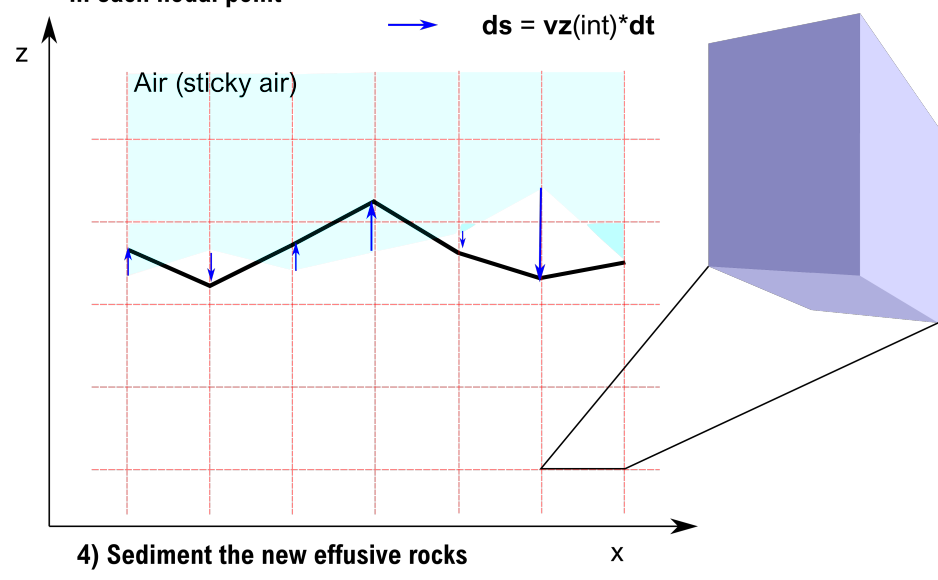

$\delta_{\text {eff }}=\mathrm{Vol}_{\text {eff }} / \mathrm{A}$

The total volume of effusive melt is divided by the cell area obtaining an effective thickness. Then the effective thickness is interpolated into the main grid

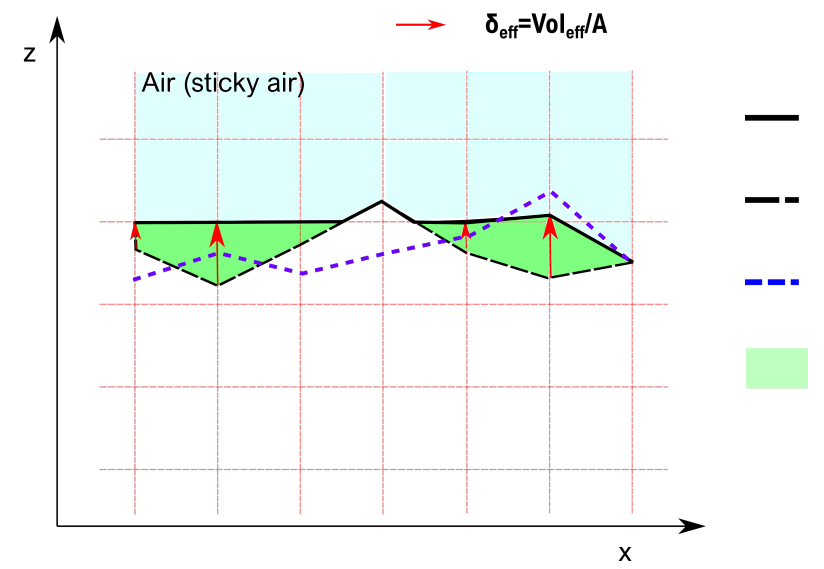

Figure S1: Simple representation of the free surface. 1) All the velocity's component are interpolated from the main grid node to the actual $z$ coordinate of the free surface; 2) The $z$ component is multiplied for the actual time-step $(d t)$, then the free surface coordinate are shifted accordingly to this displacement; 3 ) The total volume of effusion is defined in the cell center. To retrieve the effective thickness $V_{o l} l_{E f f}$ is divided by the cell area;4) The free surface is again shifted according to $\delta_{\text {eff }}$ and the difference between the previous surface and the new one is filled with the effusive phase (e.g. BS0\%). 

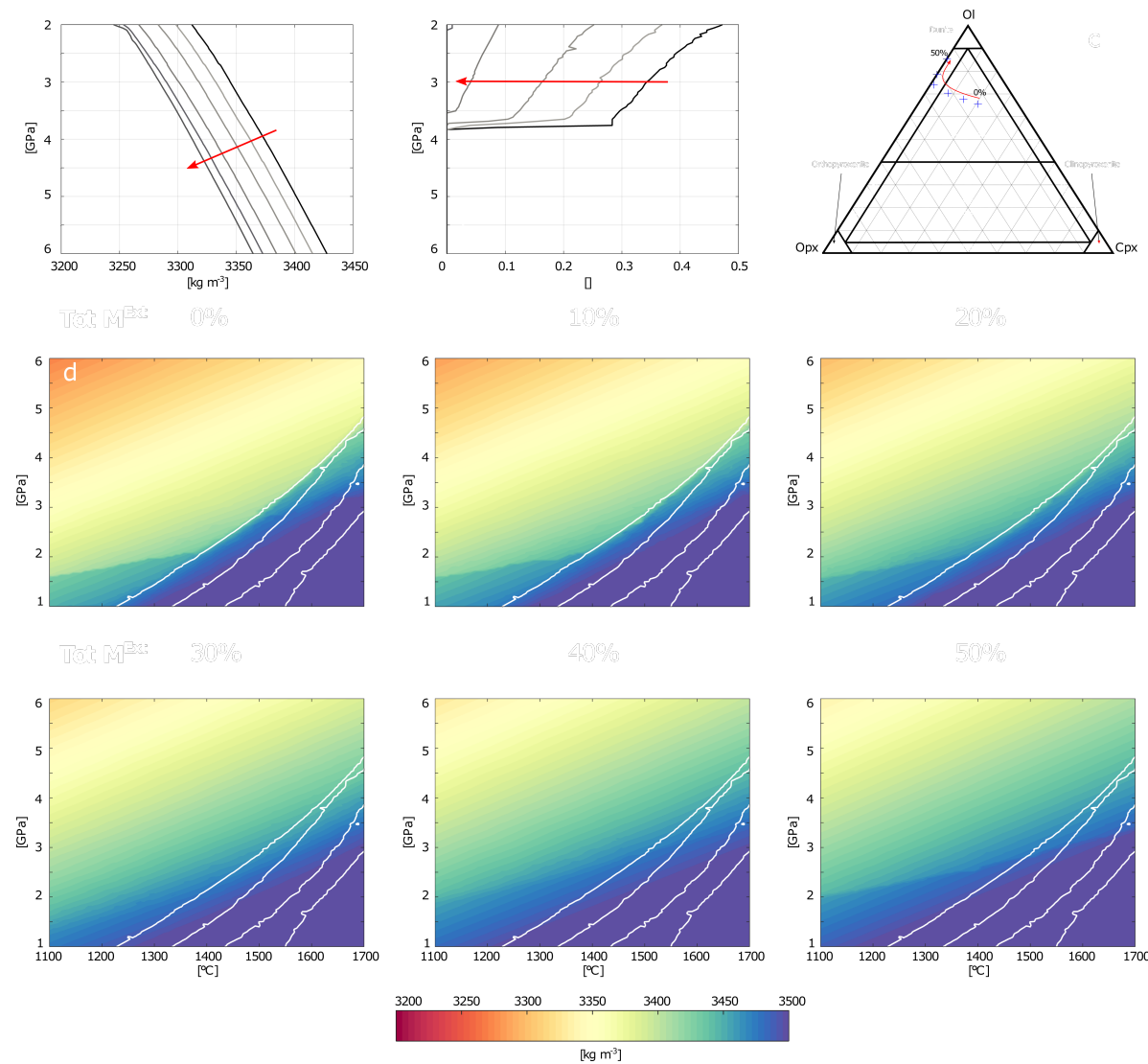

Figure S2: a): Density as a function of pressure at constant $\mathrm{T}_{P}\left(1200^{\circ} \mathrm{C}\right)$, red arrow indicate increase depletion; b): Melt quantity as a function of pressure at constant $\mathrm{T}_{P}\left(1550{ }^{\circ} \mathrm{C}\right)$, red arrow indicates the increase depletion; c): Mode amount of clinopyroxene, orthopyroxene and olivine; $\mathbf{d}$ ): Density of each depletion step. 

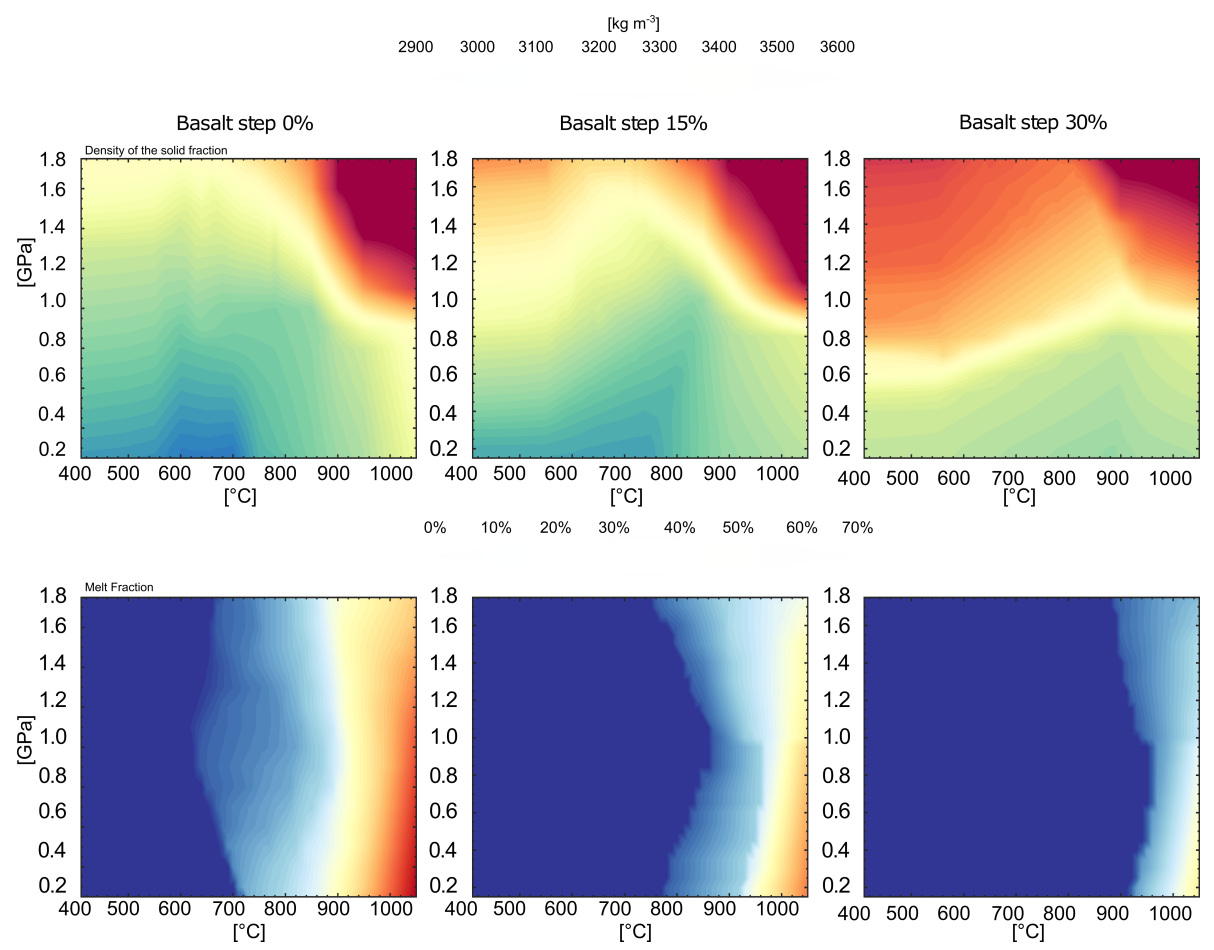

Figure S3: All these figure represents density and melt fraction as a function of $P-T$ conditions for the crustal phase diagram. The first row represents the density of the solid fraction, while the second represents the volumetric fraction of melt.

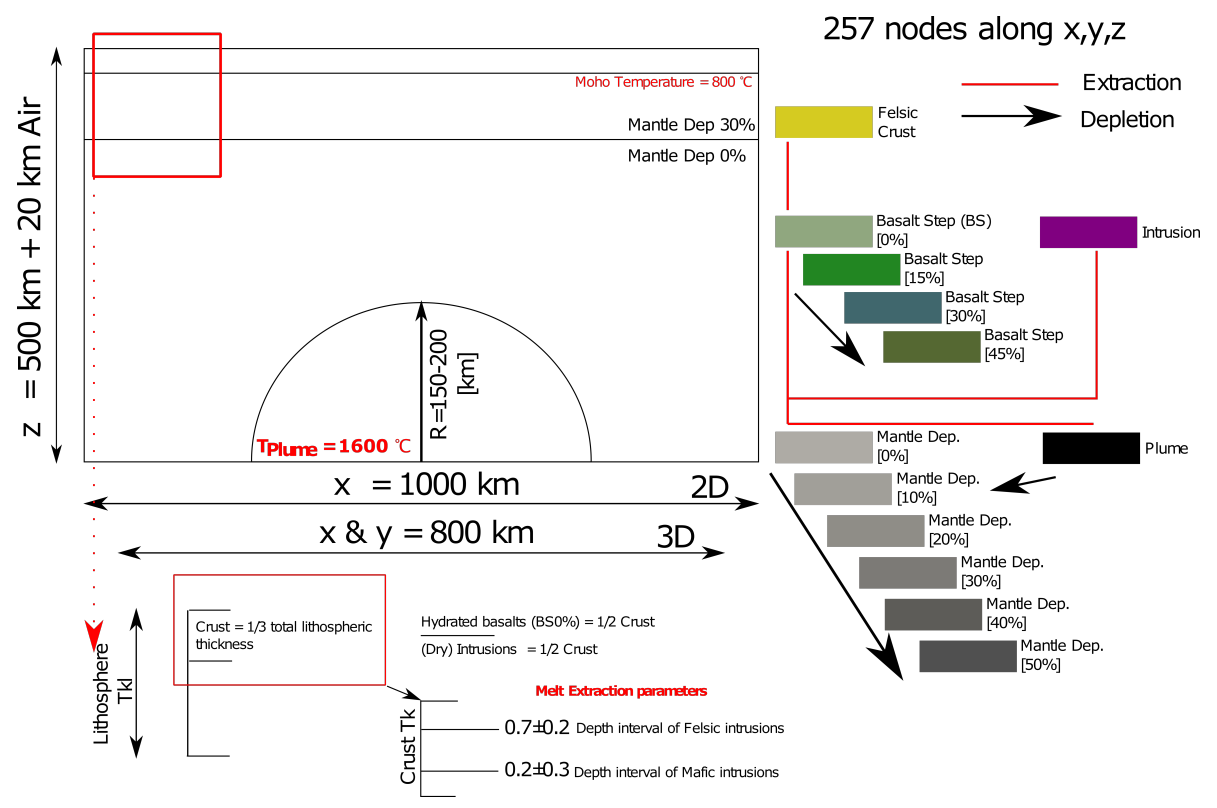

Figure S4: Initial setup. 


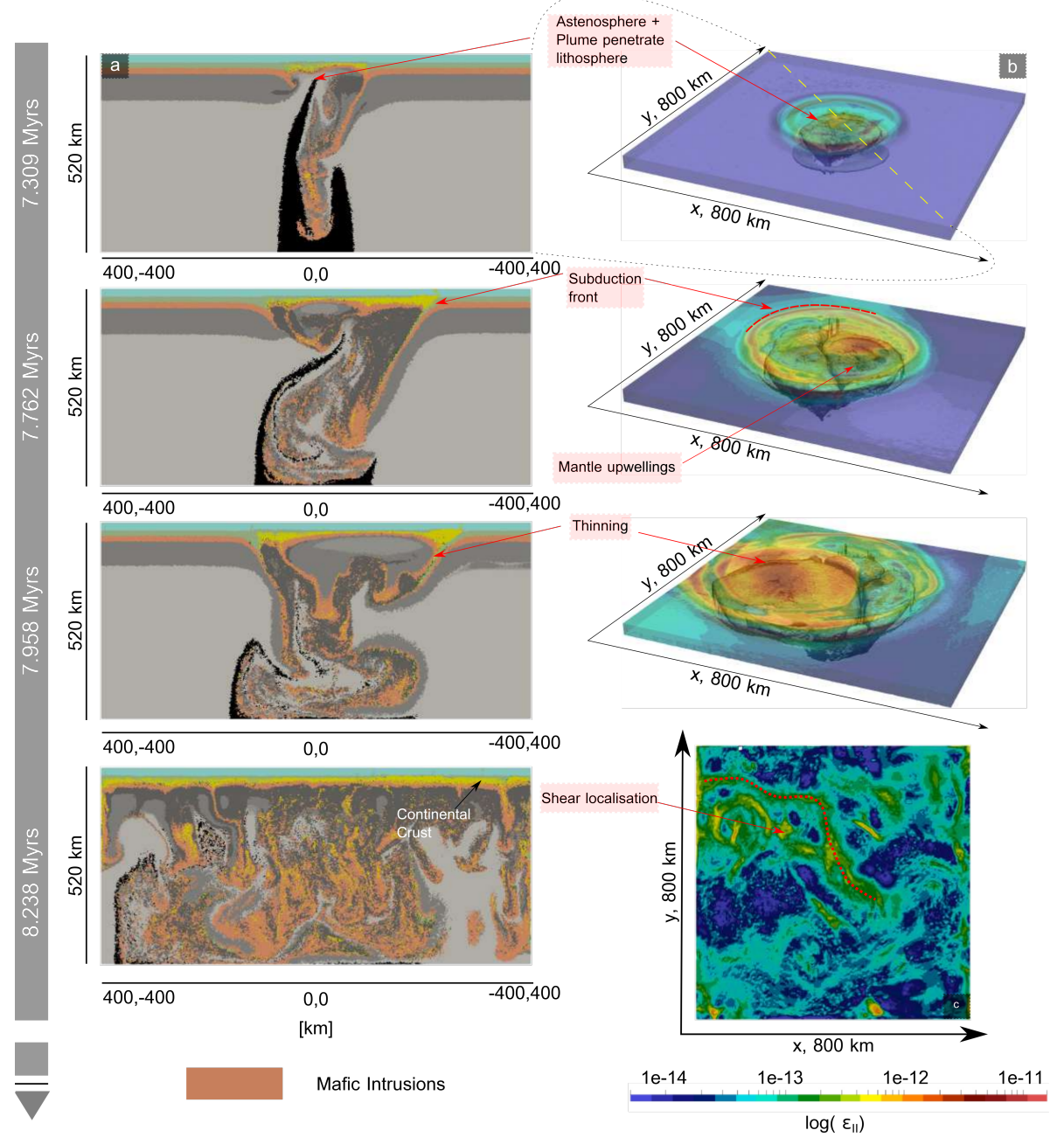

Figure S5: Inefficient melt extraction, plume radius: $150 \mathbf{~ k m}, \mathbf{d M}=\mathbf{0 . 0 0 1}$ All the picture are ordered chronologically from top to bottom. a): Compositional profile taken along a1-a2 [400 $x,-400 y][-400 x, 400 y]$; b): The transparent plot represents the strain rate state of the crust, while the gray underlying volumes is the contour of the volume of depleted mantle (the total melt extracted is $\geq 30 \%$ ); c): Planar view of the strain rate invariant. 

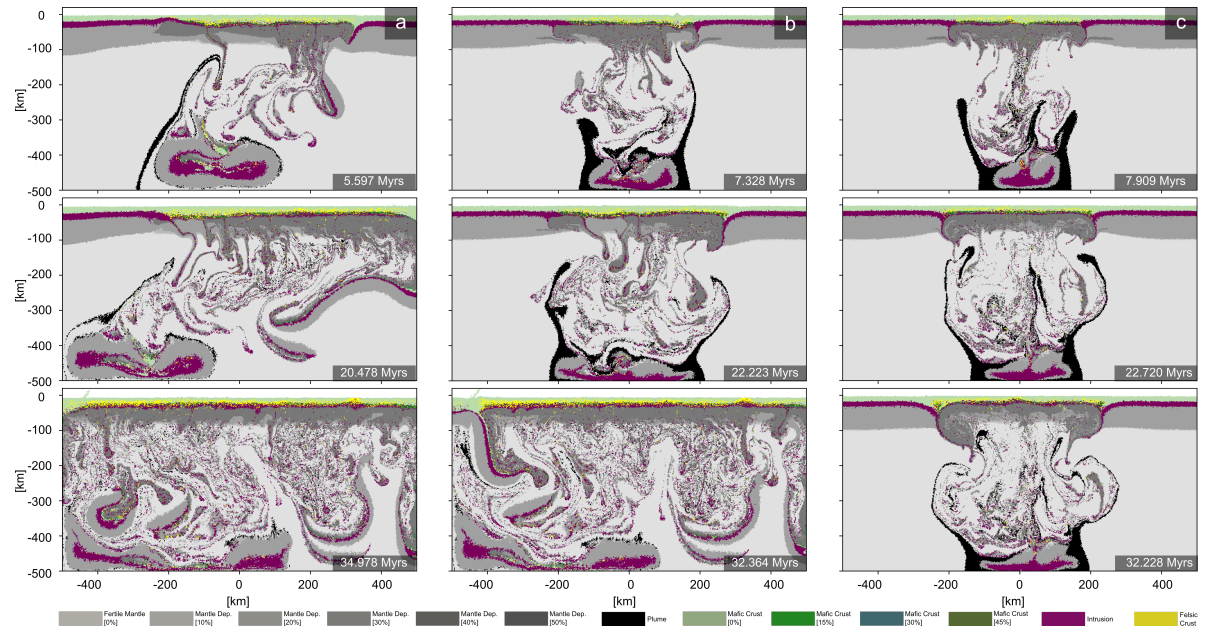

Figure S6: All experiments features the same $d M(0.05)$ and $M^{t r s}(0.001)$. a): Initial $\mathrm{T}_{P}=1400{ }^{\circ} \mathrm{C}$, lithospheric thickness, $\delta_{t k l}=100 \mathrm{~km}$ (Test $3 L_{1400}$ in Tab. S3); b): Same as $a$ except for the lithospheric thickness, $T k l=75 \mathrm{~km}\left(\right.$ Test $3 L_{1400} L T$ in Tab. S3); c): Same as $\left.b\right)$, but lower radiogenic heating and with a bottom lower thermal boundary equal to $1600^{\circ} \mathrm{C}$ (Test $3 L_{1400} L R-L T$ in Tab. S3).
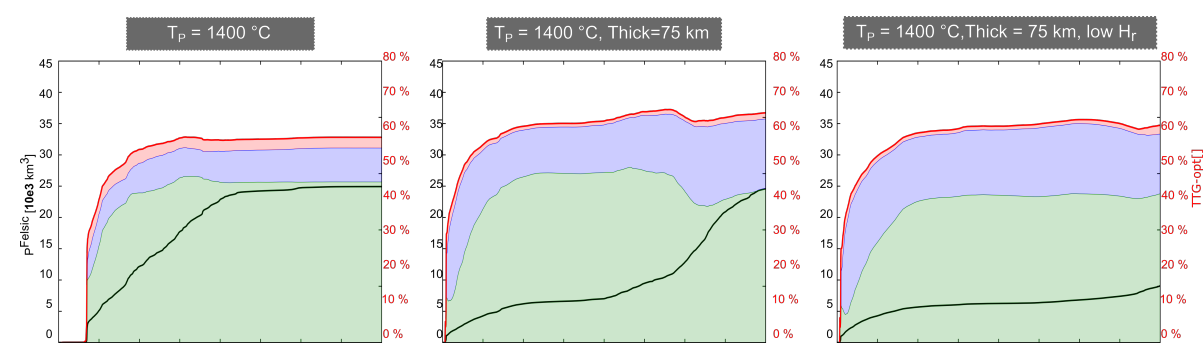

Figure S7: All the experiments are shown in Fig.S6, the list of input parameter are listed in Tab.S3. a): Each sub-plot has two $y$ axes. Left $y$ axis: $P^{\text {Felsic }}$ against time. The black tick line refers to the left axis and depict the evolution of the total volume of felsic melt extracted with time; Right y axis: TTG - opt against time. TTG - opt represents the amount of felsic melts extracted within the optimum field with time. The red thick line represents the proportion of TTG-like melts. The shaded coloured area represents the relative proportion of the three different categories: green: LP-TTG like melts; blue: MP-TTG like melts; red: HP-TTG like melts. 

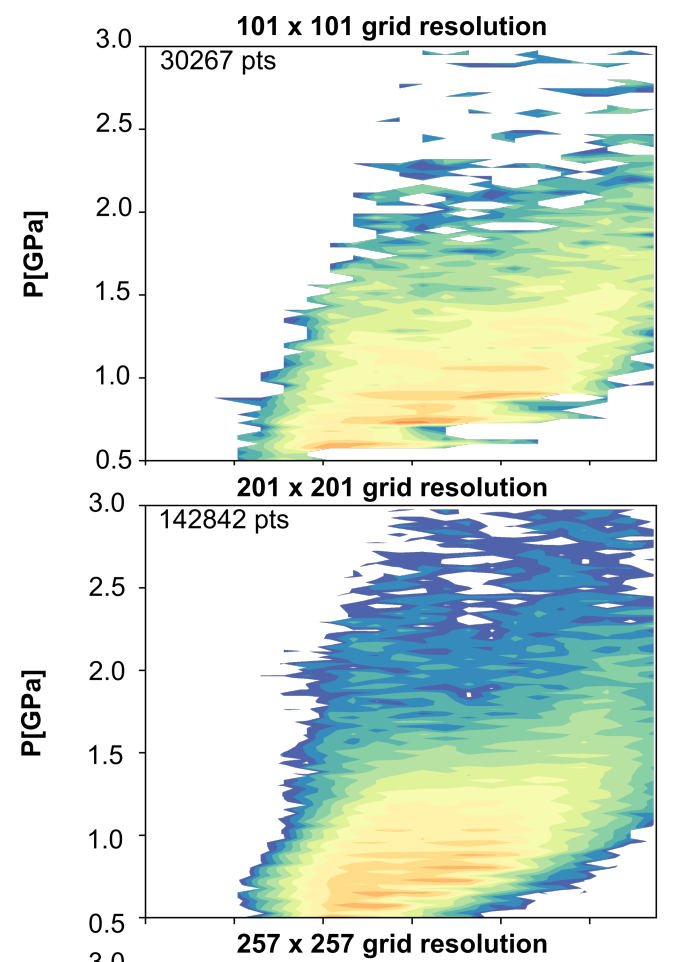

$301 \times 301$ grid resolution

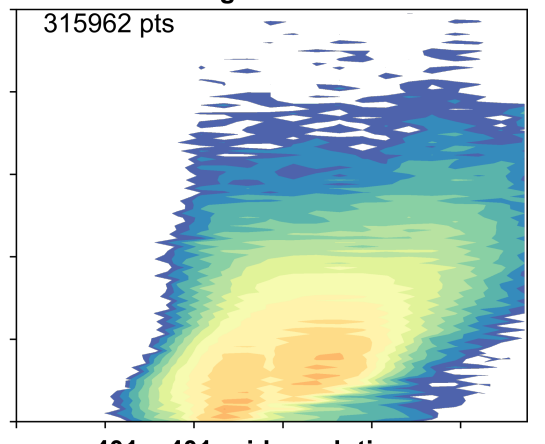

$401 \times 401$ grid resolution
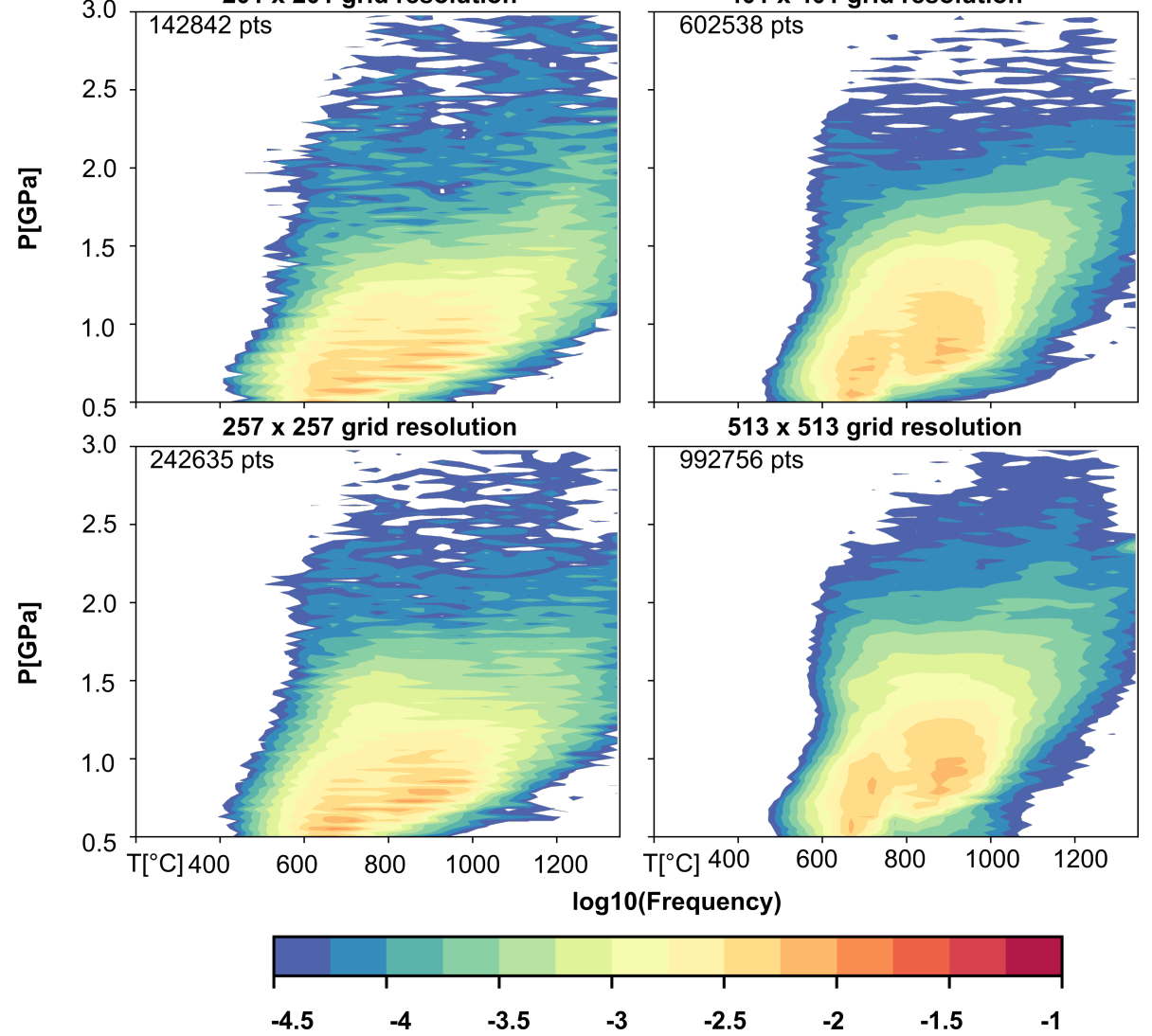

Figure S8: This figure represents the condition at which the felsic melts have been extracted during the whole simulation. We subdivided the $P-T$ space is small elements $\left(\mathrm{dP}=0.02 \mathrm{GPa} \mathrm{dT}=50{ }^{\circ} \mathrm{C}\right)$, and we compute the logarithmic frequency of felsic melts extracted in each of these small elements. We performed this operation for the whole resolution experiments. These figure testify that in all the numerical experiments there are not dramatic difference in melt extraction pattern, what is changing effectively is the frequency of occurrence of the felsic melt extraction. As a function of the resolution the number of points that we collect increases (we highlight the number of point at the upper left corner of each sub-figure). The proportion of LP-MP-HP TTGs (listed in Tab. S4) are affected by the resolution of the crust. 
A PREPRINT - FridAy $21^{\text {ST }}$ MAY, 2021

\section{References}

Anhaeusser, C. R. (2014). Archaean greenstone belts and associated granitic rocks-a review. fournal of African Earth Sciences, 100, 684-732.

Arndt, N. T. (2013). The formation and evolution of the continental crust. Geochemical Perspectives, 2, 405.

Aulbach, S., \& Arndt, N. T. (2019). Eclogites as palaeodynamic archives: Evidence for warm (not hot) and depleted (but heterogeneous) archaean ambient mantle. Earth and Planetary Science Letters, 505, 162-172.

Baes, M., Gerya, T., \& Sobolev, S. V. (2016). 3-d thermo-mechanical modeling of plume-induced subduction initiation. Earth and Planetary Science Letters, 453, 193-203.

Balay, S., Abhyankar, S., Adams, M. F., Brown, J., Brune, P., Buschelman, K., Dalcin, L., Dener, A., Eijkhout, V., Gropp, W. D., Kaushik, D., Knepley, M. G., May, D. A., McInnes, L. C., Mills, R. T., Munson, T., Rupp, K., Sanan, P., Smith, B. F., Zampini, S., Zhang, H., \& Zhang, H. (2018). PETSc Users Manual. Technical Report ANL-95/11 - Revision 3.10 Argonne National Laboratory. URL: http : / /wWw . mcs . anl . gov/petsc.

Beall, A. P., Moresi, L., \& Stern, T. (2017). Dripping or delamination? a range of mechanisms for removing the lower crust or lithosphere. Geophysical fournal International, 210, 671-692.

Bédard, J. H. (2006). A catalytic delamination-driven model for coupled genesis of Archaean crust and sub-continental lithospheric mantle. Geochimica et Cosmochimica Acta, 70, 1188-1214.

Bédard, J. H. (2018). Stagnant lids and mantle overturns: implications for archaean tectonics, magmagenesis, crustal growth, mantle evolution, and the start of plate tectonics. Geoscience Frontiers, 9, 19-49.

Bodorkos, S., Sandiford, M., Benn, K., Mareschal, J., \& Condie, K. (2006). Thermal and mechanical controls on the evolution of archean crustal deformation: examples from western australia. GEOPHYSICAL MONOGRAPHAMERICAN GEOPHYSICAL UNION, 164, 131.

Bouhallier, H., Chardon, D., \& Choukroune, P. (1995). Strain patterns in Archaean dome-and-basin structures: The Dharwar craton (Karnataka, South India). Earth and Planetary Science Letters, 135, 57-75. doi:https://doi.org/10.1016/0012821X(95)00144-2.

Chardon, D., Choukroune, P., \& Jayananda, M. (1996). Strain patterns, décollement and incipient sagducted greenstone terrains in the archaean dharwar craton (south india). Journal of Structural Geology, 18, 991-1004.

Chardon, D., Choukroune, P., \& Jayananda, M. (1998). Sinking of the dharwar basin (south india): implications for archaean tectonics. Precambrian Research, 91, 15-39.

Choukroune, P., Bouhallier, H., \& Arndt, N. (1995). Soft lithosphere during periods of archaean crustal growth or crustal reworking. Geological Society, London, Special Publications, 95, 67-86.

Collins, W., Van Kranendonk, M., \& Teyssier, C. (1998). Partial convective overturn of archaean crust in the east pilbara craton, western australia: driving mechanisms and tectonic implications. fournal of Structural Geology, 20, $1405-1424$

Condie, K. C. (1981). Archean greenstone belts volume 3. Elsevier.

Condie, K. C. (1993). Chemical composition and evolution of the upper continental crust: contrasting results from surface samples and shales. Chemical geology, 104, 1-37.

Connolly, J. (2009). The geodynamic equation of state: what and how. Geochemistry, Geophysics, Geosystems, 10.

Cox, K. G. (1980). A Model for Flood Basalt Vulcanism. Journal of Petrology, 21, 629-650. URL: http://dx.doi.org/10.1093/petrology/21.4.629.

Crisp, J. A. (1984). Rates of magma emplacement and volcanic output. Fournal of Volcanology and Geothermal Research, 20, 177-211.

Davaille, A., \& Jaupart, C. (1993). Transient high-rayleigh-number thermal convection with large viscosity variations. Journal of Fluid Mechanics, 253, 141-166.

Drucker, D. C., \& Prager, W. (1952). Soil mechanics and plastic analysis or limit design. Quarterly of applied mathematics, 10, 157-165.

Fischer, R., \& Gerya, T. (2016). Early earth plume-lid tectonics: A high-resolution 3d numerical modelling approach. fournal of Geodynamics, 100, 198-214.

François, C., Philippot, P., Rey, P., \& Rubatto, D. (2014). Burial and exhumation during archean sagduction in the east pilbara granite-greenstone terrane. Earth and Planetary Science Letters, 396, 235-251.

Ganne, J., \& Feng, X. (2017). Primary magmas and mantle temperatures through time. Geochemistry, Geophysics, Geosystems, 18, 872-888. URL: https : //doi .org/10 . 1002/2016GC006787. doi:10.1002/2016GC006787. 
Gerya, T. V., Stern, R. J., Baes, M., Sobolev, S. V., \& Whattam, S. A. (2015). Plate tectonics on the Earth triggered by plume-induced subduction initiation. Nature, 527, 221-225.

Göğüş, O. H., \& Ueda, K. (2018). Peeling back the lithosphere: Controlling parameters, surface expressions and the future directions in delamination modeling. Journal of Geodynamics, 117, 21-40.

Green, E. C. R., White, R. W., Diener, J. F. A., Powell, R., Holland, T. J. B., \& Palin, R. M. (2016). Activity-composition relations for the calculation of partial melting equilibria in metabasic rocks. Journal of Metamorphic Geology, 34, $845-869$.

Harris, L. B., \& Bédard, J. H. (2014). Crustal evolution and deformation in a non-plate-tectonic archaean earth: Comparisons with venus. In Evolution of Archean crust and early life (pp. 215-291). Springer.

Herzberg, C. T., Condie, K. C., \& Korenaga, J. (2010). Thermal history of the Earth and its petrological expression. Earth and Planetary Science Letters, 292, 79-88. URL: http://dx.doi.org/10.1016/j.eps1.2010.01.022. doi:10.1016/j.epsl.2010.01.022.

Hickman, A. H., \& Van Kranendonk, M. J. (2012). Early Earth evolution: evidence from the 3.5-1.8 Ga geological history of the Pilbara region of Western Australia. Episodes, 35, 283-297.

Hirth, G., \& Kohlstedt, D. (2004). Rheology of the upper mantle and the mantle wedge: A view from the experimentalists. Inside the subduction Factory, 138, 83-105.

Holland, T. J. B., \& Powell, R. (2003). Activity-composition relations for phases in petrological calculations: an asymmetric multicomponent formulation. Contributions to Mineralogy and Petrology, 145, 492-501.

Holland, T. J. B., \& Powell, R. (2011). An improved and extended internally consistent thermodynamic dataset for phases of petrological interest, involving a new equation of state for solids. fournal of Metamorphic Geology, 29, 333-383.

Jain, C., Rozel, A. B., Tackley, P. J., Sanan, P., \& Gerya, T. V. (2019). Growing primordial continental crust selfconsistently in global mantle convection models. Gondwana Research, 73, 96-122.

Jellinek, A. M., Lenardic, A., \& Manga, M. (2002). The influence of interior mantle temperature on the structure of plumes: Heads for venus, tails for the earth. Geophysical research letters, 29, 27-1.

Jennings, E. S., \& Holland, T. J. (2015). A simple thermodynamic model for melting of peridotite in the system ncfmasocr. Journal of Petrology, 56, 869-892.

Johnson, T. E., Brown, M., Gardiner, N. J., Kirkland, C. L., \& Smithies, R. H. (2017). Earth's first stable continents did not form by subduction. Nature, 543, 239-242.

Kamber, B. S. (2010). Archean mafic-ultramafic volcanic landmasses and their effect on ocean-atmosphere chemistry. Chemical Geology, 274, 19-28.

Kamber, B. S. (2015). The evolving nature of terrestrial crust from the hadean, through the archaean, into the proterozoic. Precambrian Research, 258, 48-82.

Kaus, B. J., Popov, A. A., Baumann, T., Pusok, A., Bauville, A., Fernandez, N., \& Collignon, M. (2016). Forward and inverse modelling of lithospheric deformation on geological timescales. In Proceedings of NIC Symposium.

Kump, L. R., \& Barley, M. E. (2007). Increased subaerial volcanism and the rise of atmospheric oxygen 2.5 billion years ago. Nature, 448, 1033-1036. URL: http://dx.doi.org/10.1038/nature06058 http://www. nature.com/nature/journal/v448/n7157/suppinfo/nature06058_S1.html.

Laurent, O., Martin, H., Moyen, J.-F., \& Doucelance, R. (2014). The diversity and evolution of late-archean granitoids: Evidence for the onset of "modern-style" plate tectonics between 3.0 and 2.5 ga. Lithos, 205, 208-235.

Le Pourhiet, L., Gurnis, M., \& Saleeby, J. (2006). Mantle instability beneath the sierra nevada mountains in california and death valley extension. Earth and Planetary Science Letters, 251, 104-119.

Lee, C.-T. A., Cheng, X., \& Horodyskyj, U. (2006). The development and refinement of continental arcs by primary basaltic magmatism, garnet pyroxenite accumulation, basaltic recharge and delamination: insights from the sierra nevada, california. Contributions to Mineralogy and Petrology, 151, 222-242.

Macpherson, C. G., Dreher, S. T., \& Thirlwall, M. F. (2006). Adakites without slab melting: high pressure differentiation of island arc magma, mindanao, the philippines. Earth and Planetary Science Letters, 243, 581-593.

McDonough, W. F., \& Sun, S.-S. (1995). The composition of the earth. Chemical geology, 120, 223-253.

Molnar, P., Houseman, G. A., \& Conrad, C. P. (1998). Rayleigh-taylor instability and convective thinning of mechanically thickened lithosphere: effects of non-linear viscosity decreasing exponentially with depth and of horizontal shortening of the layer. Geophysical fournal International, 133, 568-584. 
Morency, C., \& Doin, M.-P. (2004). Numerical simulations of the mantle lithosphere delamination. Fournal of Geophysical Research: Solid Earth, 109.

Moyen, J. F. (2011). The composite Archaean grey gneisses: Petrological significance, and evidence for a non-unique tectonic setting for Archaean crustal growth. Lithos, 123, 21-36. doi:https://doi.org/10.1016/j.lithos.2010.09.015.

Moyen, J. F., \& Martin, H. (2012). Forty years of TTG research. Lithos, 148, 312-336.

Moyen, J. F., \& Stevens, G. (2006). Experimental constraints on TTG petrogenesis: implications for Archean geodynamics. Archean geodynamics and environments, (pp. 149-175).

Nutman, A. P., Bennett, V. C., Friend, C. R., Hidaka, H., Yi, K., Lee, S. R., \& Kamiichi, T. (2013). The itsaq gneiss complex of greenland: Episodic 3900 to 3660 ma juvenile crust formation and recycling in the 3660 to 3600 ma isukasian orogeny. American fournal of Science, 313, 877-911.

Nutman, A. P., Friend, C. R., \& Paxton, S. (2009). Detrital zircon sedimentary provenance ages for the eoarchaean isua supracrustal belt southern west greenland: Juxtaposition of an imbricated ca. 3700 ma juvenile arc against an older complex with 3920-3760 ma components. Precambrian Research, 172, 212-233.

Palin, R. M., \& Dyck, B. (2018). Metamorphic consequences of secular changes in oceanic crust composition and implications for uniformitarianism in the geological record. Geoscience Frontiers, 9, 1009-1019.

Palin, R. M., Santosh, M., Cao, W., Li, S.-S., Hernández-Uribe, D., \& Parsons, A. (2020). Secular change and the onset of plate tectonics on earth. Earth-Science Reviews, (p. 103172).

Palin, R. M., \& White, R. W. (2016). Emergence of blueschists on earth linked to secular changes in oceanic crust composition. Nature Geoscience, 1, 60-64.

Palin, R. M., White, R. W., \& Green, E. C. (2016a). Partial melting of metabasic rocks and the generation of tonalitictrondhjemitic-granodioritic (ttg) crust in the archaean: Constraints from phase equilibrium modelling. Precambrian Research, 287, 73-90.

Palin, R. M., White, R. W., Green, E. C., Diener, J. F., Powell, R., \& Holland, T. J. (2016b). High-grade metamorphism and partial melting of basic and intermediate rocks. Journal of Metamorphic Geology, 34, 871-892.

Piccolo, A., Palin, R. M., Kaus, B. J., \& White, R. W. (2019). Generation of earth's early continents from a relatively cool archean mantle. Geochemistry, Geophysics, Geosystems, 20, 1679-1697.

Powell, R., \& Holland, T. (1988). An internally consistent dataset with uncertainties and correlations: 3. applications to geobarometry, worked examples and a computer program. Fournal of metamorphic Geology, 6, 173-204.

Ranalli, G. (1995). Rheology of the earth, 413 pp.

Reuber, G. S., Kaus, B. J. P., Popov, A. A., \& Baumann, T. S. (2018). Unraveling the physics of the yellowstone magmatic system using geodynamic simulations. Frontiers in Earth Science, 6, 117.

Rey, P. F., Coltice, N., \& Flament, N. (2014). Spreading continents kick-started plate tectonics. Nature, 513, 405-408.

Rozel, A. B., Golabek, G. J., Jain, C., Tackley, P. J., \& Gerya, T. V. (2017). Continental crust formation on early Earth controlled by intrusive magmatism. Nature, 545, 47-52.

Rummel, L., Kaus, B. J., White, R. W., Mertz, D. F., Yang, J., \& Baumann, T. S. (2018). Coupled petrological-geodynamical modeling of a compositionally heterogeneous mantle plume. Tectonophysics, 723, 242-260.

Schubert, G., Turcotte, D. L., \& Olson, P. (2001). Mantle convection in the Earth and planets. Cambridge University Press.

Sizova, E., Gerya, T., \& Brown, M. (2014). Contrasting styles of phanerozoic and precambrian continental collision. Gondwana Research, 25, 522-545.

Sizova, E., Gerya, T. V., Stüwe, K., \& Brown, M. (2015). Generation of felsic crust in the Archean: A geodynamic modeling perspective. Precambrian Research, 271, 198-224. URL: http://dx.doi.org/10.1016/j.precamres.2015.10.005. doi:10.1016/j.precamres.2015.10.005.

Smithies, R. H., Champion, D. C., \& Van Kranendonk, M. J. (2009). Formation of Paleoarchean continental crust through infracrustal melting of enriched basalt. Earth and Planetary Science Letters, 281, 298-306.

Smithies, R. H., Lu, Y., Johnson, T. E., Kirkland, C. L., Cassidy, K. F., Champion, D. C., Mole, D. R., Zibra, I., Gessner, K., Sapkota, J. et al. (2019). No evidence for high-pressure melting of earth's crust in the archean. Nature Communications, 10, 1-12.

Solomatov, V. (1995). Scaling of temperature-and stress-dependent viscosity convection. Physics of Fluids, 7, 266-274. 
Stofan, E. R., Sharpton, V. L., Schubert, G., Baer, G., Bindschadler, D. L., Janes, D. M., \& Squyres, S. W. (1992). Global distribution and characteristics of coronae and related features on venus: Implications for origin and relation to mantle processes. Journal of Geophysical Research: Planets, 97, 13347-13378.

Ueda, K., Gerya, T., \& Sobolev, S. V. (2008). Subduction initiation by thermal-chemical plumes: numerical studies. Physics of the Earth and Planetary Interiors, 171, 296-312.

Van Kranendonk, M. J. (2010). Two types of Archean continental crust: Plume and plate tectonics on early Earth. American fournal of Science, 310, 1187-1209.

Van Kranendonk, M. J., Collins, W., Hickman, A., \& Pawley, M. J. (2004). Critical tests of vertical vs. horizontal tectonic models for the archaean east pilbara granite-greenstone terrane, pilbara craton, western australia. Precambrian Research, 131, 173-211.

Van Kranendonk, M. J., Hugh Smithies, R., Hickman, A. H., \& Champion, D. (2007). secular tectonic evolution of archean continental crust: interplay between horizontal and vertical processes in the formation of the pilbara craton, australia. Terra Nova, 19, 1-38.

Van Kranendonk, M. J., Smithies, R. H., Griffin, W. L., Huston, D. L., Hickman, A. H., Champion, D. C., Anhaeusser, C. R., \& Pirajno, F. (2015). Making it thick: a volcanic plateau origin of palaeoarchean continental lithosphere of the pilbara and kaapvaal cratons. Geological Society, London, Special Publications, 389, 83-111.

Wallner, H., \& Schmeling, H. (2016). Numerical models of mantle lithosphere weakening, erosion and delamination induced by melt extraction and emplacement. International fournal of Earth Sciences, 105, 1741-1760.

White, R., Powell, R., \& Clarke, G. L. (2002). The interpretation of reaction textures in Fe-rich metapelitic granulites of the Musgrave Block, central Australia: constraints from mineral equilibria calculations in the system $\mathrm{K}_{2} \mathrm{O}-\mathrm{FeO}-$ $\mathrm{MgO}-\mathrm{Al}_{2} \mathrm{O}_{3}-\mathrm{SiO}_{2}-\mathrm{H}_{2} \mathrm{O}-\mathrm{TiO}_{2}-\mathrm{Fe}_{2} \mathrm{O}_{3}$. Fournal of metamorphic Geology, 20, 41-55.

White, R. W., Palin, R. M., \& Green, E. C. R. (2017). High-grade metamorphism and partial melting in Archean composite grey gneiss complexes. Journal of Metamorphic Geology, 35, 181-195. doi:10.1111/jmg.12227.

White, R. W., Powell, R., Holland, T. J. B., Johnson, T. E., \& Green, E. C. R. (2014). New mineral activity-composition relations for thermodynamic calculations in metapelitic systems. Journal of Metamorphic Geology, 32, 261-286.

White, R. W., Powell, R., Holland, T. J. B., \& Worley, B. A. (2000). The effect of $\mathrm{TiO}_{2}$ and $\mathrm{Fe}_{2} \mathrm{O}_{3}$ on metapelitic assemblages at greenschist and amphibolite facies conditions: mineral equilibria calculations in the system $\mathrm{K}_{2} \mathrm{O}$ $\mathrm{FeO}-\mathrm{MgO}-\mathrm{Al}_{2} \mathrm{O}_{3}-\mathrm{SiO}_{2}-\mathrm{H}_{2} \mathrm{O}-\mathrm{TiO}_{2}-\mathrm{Fe}_{2} \mathrm{O}_{3}$. Fournal of Metamorphic Geology, 18, 497-512.

White, S. M., Crisp, J. A., \& Spera, F. J. (2006). Long-term volumetric eruption rates and magma budgets. Geochemistry, Geophysics, Geosystems, 7.

Zegers, T. E., \& van Keken, P. E. (2001). Middle Archean continent formation by crustal delamination. Geology, 29, $1083-1086$ 